\title{
Evaluation of exposures and respiratory health at a coffee roasting and packaging facility and associated café
}

Stephen B. Martin, Jr., Ph.D., PE Ryan F. LeBouf, Ph.D., CIH Marcia L. Stanton, BS Rachel L. Bailey, DO, MPH

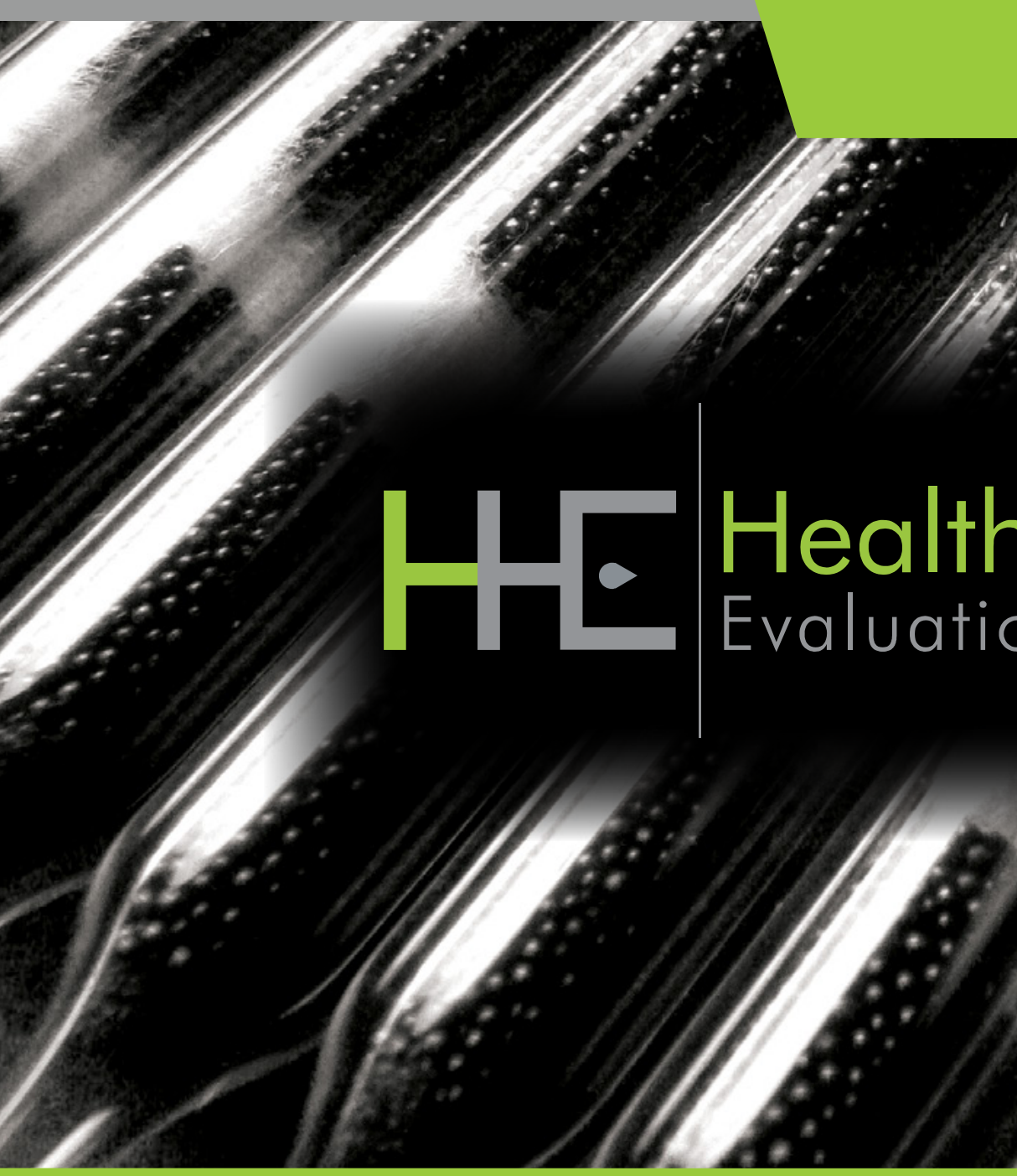

Report No. 2016-0067-3313

April 2018

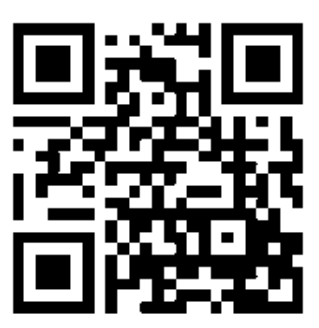

U.S. Department of Health and Human Services Centers for Disease Control and Prevention National Institute for Occupational Safety and Health

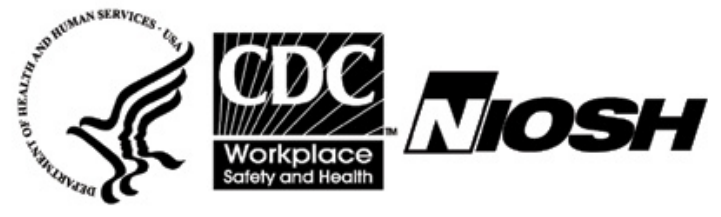




\section{Contents}

Highlights..............................................i

Abbreviations ..................................... vi

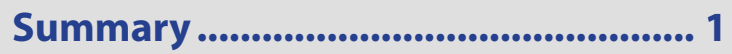

Introduction ...................................... 3

Background.......................................... 3

Process Description ............................. 7

Methods ............................................... 9

Results ......................................... 15

Discussion ...................................... 22

Conclusions ..................................... 29

Recommendations.............................. 29

Appendix A: Facility Tables ............... 33

Appendix B: Café Tables................... 40

Appendix C: Figures ........................... 43

References........................................ 44

Acknowledgements.......................... 54

The employer is required to post a copy of this report for 30 days at or near the workplace(s) of affected employees. The employer must take steps to ensure that the posted report is not altered, defaced, or covered by other material.

The cover photo is a close-up image of sorbent tubes, which are used by the HHE Program to measure airborne exposures. This photo is an artistic representation that may not be related to this Health Hazard Evaluation. 


\section{Highlights of this Evaluation}

The Health Hazard Evaluation Program received a request from management at a coffee roasting and packaging facility and café with concerns about the potential health effects from exposure to diacetyl during coffee roasting, grinding, storing, packaging, and café tasks.

\section{Coffee Roasting and Packaging Facility}

\section{What We Did}

- We visited the coffee roasting and packaging facility in March 2016.

- We collected average (hours), task (minutes), and instantaneous (seconds) air samples to measure levels of alpha-diketones (diacetyl, 2,3-pentanedione, and 2,3-hexanedione).

- We collected green coffee beans and roasted whole bean coffee to measure their emission potential for diacetyl, 2,3-pentanedione, and 2,3-hexanedione.

- We measured real-time air levels of total volatile organic compounds, carbon monoxide, and carbon dioxide.

- We assessed the ventilation system.

- We interviewed employees and performed breathing tests.

\section{What We Found}

- All full-shift personal air sampling results were below the recommended exposure limits for diacetyl ( 5 parts per billion) and 2,3-pentanedione (9.3 parts per billion), with the highest measured concentrations of 4.7 parts per billion for diacetyl and 3.9 parts per billion for 2,3-pentanedione in the production area.

- All 15-minute personal task-based samples were below the recommended short-term exposure limits for diacetyl (25 parts per billion) and 2,3-pentanedione (31 parts per billion).

\section{Coffee Roasting and Packaging Facility}

We evaluated respiratory health and airborne exposures to alphadiketones (diacetyl, 2,3-pentanedione, and 2,3-hexanedione), other volatile organic compounds, carbon monoxide, and carbon dioxide at a coffee packaging and roasting facility. All full-shift personal air samples were below the recommended exposure limits for diacetyl and 2,3-pentanedione. Grinding tasks in the production area resulted in the highest alpha-diketone exposures. Samples taken with instantaneous evacuated canisters also showed higher alpha-diketone concentrations associated with grinding activities. Carbon dioxide and carbon monoxide concentrations in the air did not exceed applicable exposure limits. Eye and nose symptoms were the most commonly reported symptoms. Some employees reported their symptoms were caused or aggravated by dust, green coffee dust, and chaff. Breathing trouble and awakening with chest tightness were the most commonly reported lower respiratory symptoms. All spirometry tests were normal; two of ten participants had high exhaled nitric oxide, a marker of allergic airways inflammation. We recommend operating the rooftop air-handling unit at all times during production activities, implementing administrative controls such as modification of work practices, training employees about workplace hazards, and voluntary use of N95 disposable filtering facepiece respirators available for protection against green or roasted coffee dust exposure such as when working with green coffee beans or chaff. 
- Grinding tasks in the production area resulted in the highest alpha-diketone exposures (9.4 parts per billion diacetyl; 9.9 parts per billion 2,3-pentanedione). Samples taken with instantaneous evacuated canisters also showed higher alpha-diketone concentrations associated with grinding activities.

- Diacetyl and 2,3-pentanedione air concentrations increased over the day.

- Tested roasted coffee beans emitted diacetyl and 2,3-pentanedione; 2,3-hexanedione was below the limit of detection.

- Carbon dioxide and carbon monoxide concentrations in the air did not exceed applicable exposure limits. Maximum carbon dioxide levels were at the roaster (627 parts per billion) and in the packaging area (691 parts per billion). The maximum carbon monoxide level measured was in packaging (4 parts per billion).

- The rooftop air-handling unit, office furnace, dust-collection system, and associated ductwork at the production facility were all well maintained and in good working order.

- Differential pressures, and subsequently the direction of air flow, between the roasting and packaging space and the non-production areas were impacted by the on/off status of the air-handling units. In some scenarios, airborne contaminants from the roasting and packaging space could be pulled into the quality control café and reception office.

- Eye and nose symptoms were the most commonly reported symptoms. Some employees reported their symptoms were caused or aggravated by dust, green coffee dust, or chaff.

- Breathing trouble and awakening with chest tightness were the most commonly reported lower respiratory symptoms.

- All spirometry tests were normal; two of ten participants had high exhaled nitric oxide, a marker of allergic airways inflammation.

\section{What the Employer Can Do}

- Ensure employees understand potential hazards (e.g., diacetyl, 2,3-pentanedione, carbon monoxide, carbon dioxide, green and roasted coffee dust) in the workplace and how to protect themselves.

- Minimize production tasks that require employees to place their heads inside roasted bean bins.

- Run the rooftop air-handling unit at all times during production activities.

- Install better seals, including floor sweeps on the two doors between the production space and the quality control café and reception areas.

- If increases to production volumes, modification to current work practices, and/ or changes in ventilation occur, conduct additional air sampling to verify that the modifications have not resulted in alpha-diketone exposures above the NIOSH recommended exposure limits. Install additional engineering controls if they become necessary. 
- Make N95 disposable filtering facepiece respirators available for voluntary use for protection against dust exposure, such as when working with green coffee beans and chaff.

- Encourage employees to report new, worsening, or ongoing respiratory symptoms to their personal healthcare providers and to a designated individual at the workplace.

\section{What Employees Can Do}

- As much as possible, avoid placing your head directly inside roasted bean storage bins or directly outside uncovered bins containing roasted coffee.

- Some employees may wish to use N95 disposable filtering facepiece respirators for some tasks, such as when working with green coffee beans or chaff.

- Report new, persistent, or worsening respiratory symptoms to your personal healthcare provider(s) and a designated individual at your workplace.

\section{Café}

\section{What We Did}

- We visited the café in March 2016.

- We collected average (hours), task (minutes), and instantaneous (seconds) air samples to measure levels of alpha-diketones (diacetyl, 2,3-pentanedione, and 2,3-hexanedione).

- We measured real-time air levels of total volatile organic compounds, carbon monoxide and carbon dioxide.

- We assessed the ventilation system.

- We interviewed employees and performed breathing tests.

\section{What We Found}

- Three of the five full-shift personal air samples were above the recommended exposure limit for diacetyl of 5 parts per billion, with the highest measured concentration of 6 parts per billion. None of the personal samples exceeded the recommended exposure limit for 2,3-pentanedione.

- An employee that made espresso drinks,

\section{Café}

We evaluated respiratory health and airborne exposures to alphadiketones (diacetyl, 2,3-pentanedione, and 2,3-hexanedione), other volatile organic compounds, carbon monoxide, and carbon dioxide at a coffee café. Three of the five full-shift personal air samples were above the NIOSH recommended exposure limit for diacetyl of 5 parts per billion, with the highest measured concentration of 6 parts per billion. An employee that made espresso drinks, including grinding the coffee beans, had the highest personal task-based exposures for diacetyl and 2,3-pentanedione. Carbon dioxide levels increase slightly throughout the day and were higher than recommended. The air-handling unit that provided ventilation to the café was recirculating $100 \%$ of the air from the café spaces without bringing in any outdoor air. An adequate supply of outdoor air is necessary in any indoor environment to dilute pollutants. Nose symptoms followed by sinusitis or sinus problems were the most commonly reported symptoms; participants did not report any workrelated symptoms. All spirometry and exhaled nitric oxide tests were normal. We recommend training employees about workplace hazards and working with a ventilation expert to bring in appropriate levels of outdoor air to meet ventilation guidelines. 
including grinding the coffee beans, had the highest personal task-based exposures for diacetyl (7.3 parts per billion) and 2,3-pentanedione (9.4 parts per billion).

- Both diacetyl and 2,3-pentanedione air concentrations increased over the course of the work day.

- When measured beside the expresso machine, carbon dioxide levels increased slightly throughout the day, and were higher than recommended. The average carbon monoxide level was 1.6 parts per million, but short-term peaks of up to 109.6 parts per million were measured.

- The air-handling unit that provided ventilation to the café was recirculating $100 \%$ of the air from the café spaces without bringing in any outdoor air. Thus, the system was unable to help dilute pollutants released by equipment, building materials, furnishings, processes and products (e.g., grinding coffee), as well as people.

- Nose symptoms followed by sinusitis or sinus problems were the most commonly reported symptoms; participants did not report any work-related symptoms.

- All spirometry and exhaled nitric oxide tests were normal.

\section{What the Employer Can Do}

- Ensure employees understand potential hazards (e.g., diacetyl, 2,3-pentanedione, carbon dioxide, roasted coffee dust) in the workplace and how to protect themselves.

- Work with a ventilation expert to introduce appropriate levels of outdoor air into the café space to meet local and state ventilation guidelines. This will also reduce airborne alpha-diketone concentrations.

- Conduct follow-up personal air sampling on employees to verify that the modifications have been effective in reducing alpha-diketone exposures below the recommended exposure limits.

- Encourage employees to report new, worsening, or ongoing respiratory symptoms to their personal healthcare providers and to a designated individual at the workplace.

\section{What Employees Can Do}

- Participate in any personal air sampling offered by your employer.

- Report new, persistent, or worsening respiratory symptoms to your personal healthcare provider(s) and a designated individual at your workplace. 
This page left intentionally blank 


\section{Abbreviations}

\begin{tabular}{|c|c|}
\hline$\mu g$ & Microgram \\
\hline $\mathrm{ACGIH}^{\oplus}$ & American Conference of Governmental Industrial Hygienists \\
\hline AHU & Air-handling unit \\
\hline ANSI & American National Standards Institute \\
\hline $\mathrm{AX}$ & Area of reactance \\
\hline $\mathrm{cfm}$ & Cubic feet per minute \\
\hline CFR & Code of Federal Regulations \\
\hline CI & Confidence interval \\
\hline $\mathrm{CO}$ & Carbon monoxide \\
\hline $\mathrm{CO}_{2}$ & Carbon dioxide \\
\hline COPD & Chronic obstructive pulmonary disease \\
\hline $\mathrm{FEV}_{1}$ & 1-second forced expiratory volume \\
\hline Fres & Resonant frequency \\
\hline $\mathrm{ft}^{2}$ & Square feet \\
\hline FVC & Forced vital capacity \\
\hline HVAC & Heating, ventilation, and air-conditioning \\
\hline LOD & Limit of detection \\
\hline $\mathrm{mL}$ & Milliliter \\
\hline $\mathrm{mL} / \mathrm{min}$ & Milliliter per minute \\
\hline NHANES & National Health and Nutrition Examination Survey \\
\hline $\mathrm{NIOSH}$ & National Institute for Occupational Safety and Health \\
\hline OEL & Occupational exposure limit \\
\hline OSHA & Occupational Safety and Health Administration \\
\hline PEL & Permissible exposure limit \\
\hline $\mathrm{ppb}$ & Parts per billion \\
\hline ppm & Parts per million \\
\hline QC & Quality control \\
\hline R5 & Resistance at $5 \mathrm{Hertz}$ \\
\hline $\mathrm{R} 20$ & Resistance at $20 \mathrm{Hertz}$ \\
\hline REL & Recommended exposure limit \\
\hline SMR & Standardized morbidity ratio \\
\hline STEL & Short-term exposure limit \\
\hline $\mathrm{TLV}^{\oplus}$ & Threshold limit value \\
\hline TVOC & Total volatile organic compound \\
\hline TWA & Time-weighted average \\
\hline VOC & Volatile organic compound \\
\hline $\mathrm{X} 5$ & Reactance at 5 Hertz \\
\hline
\end{tabular}




\section{Summary}

In January 2016, the National Institute for Occupational Safety and Health's Health Hazard Evaluation Program received a request from the management of a coffee roasting and packaging facility and associated coffee café regarding concerns about exposures to and health effects from diacetyl during coffee roasting, grinding, and café tasks. In March 2016, we conducted an industrial hygiene survey and ventilation assessment. We also performed a medical survey. The industrial hygiene survey consisted of collecting personal breathing zone and general area air samples for alpha-diketones (i.e., diacetyl, 2,3-pentanedione, and 2,3-hexanedione). Bulk samples of whole bean green and roasted coffee were collected to evaluate the potential for emission of diacetyl, 2,3-pentanedione, and 2,3-hexanedione. We used continuous monitoring instruments to measure total volatile organic compounds, carbon monoxide, carbon dioxide, temperature, and relative humidity in specific areas and during tasks. The medical survey consisted of a health questionnaire and breathing tests.

At the roasting and packaging facility, all full-shift personal air sample results were below the recommended exposure limits for diacetyl and 2,3-pentanedione. Grinding tasks in the production area resulted in the highest alpha-diketone exposures. Carbon dioxide and carbon monoxide concentrations in the air did not exceed applicable exposure limits. Eye and nose symptoms were the most commonly reported symptoms. Breathing trouble and awakening with chest tightness were the most commonly reported lower respiratory symptom. All participants with upper or lower respiratory symptoms reported that their symptoms did not improve away from work. These respiratory symptoms and the lung function abnormalities could be related to workplace exposures or to other factors. However, our findings of respiratory symptoms caused or aggravated by dust, green bean dust, or chaff in $40 \%$ of medical survey participants suggest a burden of respiratory problems in this workforce. We recommend operating the rooftop air-handling unit at all times during production activities, implementing administrative controls such as modification of work practices, training employees about workplace hazards, and voluntary use of N95 disposable filtering facepiece respirators available for protection against green or roasted coffee dust exposure such as when working with green coffee beans or chaff.

At the café, three of five full-shift personal air samples were above the recommended exposure limit for diacetyl of 5 parts per billion, with the highest measured concentration of 6 parts per billion. None of the personal samples exceeded the recommended exposure limit for 2,3-pentanedione. An employee that made espresso drinks, including grinding the coffee beans, had the highest personal task-based exposures for diacetyl and 2,3-pentanedione. Both diacetyl and 2,3-pentanedione air concentrations increased over the course of the work day. When we measured beside the expresso machine, carbon dioxide levels also increased slightly throughout the day, and were higher than recommended. The air-handling unit that provided ventilation to the café was recirculating $100 \%$ of the air from the café spaces without bringing in any outdoor air. An adequate supply of outdoor air, typically delivered through the heating, and air-conditioning system, is necessary in any indoor environment to dilute pollutants that are released by equipment, building materials, furnishing, processes and products (e.g., grinding coffee) as well as people. Nose symptoms followed by sinusitis 
or sinus problems were the most commonly reported symptoms; medical survey participants did not report any work-related symptoms. All spirometry and exhaled nitric oxide tests were normal. We recommend training employees about workplace hazards and working with a ventilation expert to bring in appropriate levels of outdoor air to meet ventilation guidelines. 


\section{Introduction}

The Health Hazard Evaluation Program of the National Institute for Occupational Safety and Health (NIOSH) received a request from management at a coffee roasting and packaging facility and an associated café with concerns about the potential health effects from exposure to diacetyl during coffee roasting, grinding, storing, packaging, and café tasks. We conducted an industrial hygiene survey at the café on March 6, 2016, and a medical survey on March 12,2016 . At the roasting and packaging facility, we conducted an industrial hygiene survey on March 14-15, 2016, and a medical survey on March 17, 2016.

\section{Background}

\section{Diacetyl and 2,3-Pentanedione}

Diacetyl (2,3-butanedione) and 2,3-pentanedione (acetyl propionyl) are volatile organic compounds (VOCs) known as alpha-diketones that are added as ingredients in food flavorings used in some food products such as microwave popcorn, bakery mixes, and flavored coffee [Day et al. 2011; Kanwal et al. 2006; Bailey et al. 2015]. Diacetyl, 2,3-pentanedione, other VOCs, and gases such as carbon monoxide (CO) and carbon dioxide $\left(\mathrm{CO}_{2}\right)$ are naturally produced and released during the coffee roasting process [Duling et al. 2016; Raffel and Thompson 2013; Daglia et al. 2007; Nishimura et al. 2003; Newton 2002]. Grinding roasted coffee beans produces a greater surface area for off-gassing (sometimes called degassing) of these compounds [Akiyama et al. 2003]. Often, coffee roasting facilities package newly roasted coffee in permeable bags or in bags fitted with one-way valves to allow the coffee to off-gas after it is packaged. Sometimes, newly roasted coffee is placed in bins or containers and allowed to off-gas before packaging.

NIOSH has recommended exposure limits (RELs) for diacetyl and 2,3-pentanedione in workplace air (Table 1) [NIOSH 2016]. The NIOSH objective in establishing RELs for diacetyl and 2,3-pentanedione is to reduce the risk of respiratory impairment (decreased lung function) and the severe irreversible lung disease obliterative bronchiolitis associated with occupational exposure to these chemicals. NIOSH RELs are intended to protect workers exposed to diacetyl or 2,3-pentanedione for a 45-year working lifetime. The REL for diacetyl is based on a quantitative risk assessment which necessarily contains assumptions and some uncertainty. Analytical limitations current at the time were taken into consideration in setting the REL for 2,3-pentanedione. The RELs should be used as a guideline to indicate when steps should be taken to reduce exposures in the workplace.

These exposure limits and the accompanying recommendations for control of exposures were derived from a risk assessment of flavoring-exposed workers. At an exposure equal to the diacetyl REL, the risk of adverse health effects is low. NIOSH estimated that about 1 in 1,000 workers exposed to diacetyl levels of 5 parts per billion (ppb) as a time-weighted average (TWA) for 8 hours a day, 40 hours a week for a 45 -year working lifetime would develop reduced lung function (defined as forced expiratory volume in one second $\left[\mathrm{FEV}_{1}\right]$ below the lower limit of normal) as a result of that exposure. NIOSH predicted that around 1 in 10,000 
workers exposed to diacetyl at $5 \mathrm{ppb}$ for a 45-year working lifetime would develop more severe lung function reduction $\left(\mathrm{FEV}_{1}\right.$ below $60 \%$ predicted, defined as at least moderately severe by the American Thoracic Society [Pellegrino et al. 2005]). Workers exposed for less time would be at lower risk for adverse lung effects.

\section{2,3-Hexanedione}

2,3-Hexanedione is also an alpha-diketone that is sometimes used as a substitute for diacetyl and is produced naturally during coffee roasting. In a study using animals, there was some evidence that 2,3-hexanedione might also damage the lungs, but it appeared to be less toxic than diacetyl and 2,3-pentanedione [Morgan et al. 2016]. There are no established occupational exposure limits for 2,3-hexanedione.

\section{Carbon Monoxide and Carbon Dioxide}

$\mathrm{CO}$ and $\mathrm{CO}_{2}$ are gases produced by combustion. They are also produced as a result of reactions that take place during coffee roasting. These gases are released during and after roasting and grinding by a process called off-gassing [Anderson et al. 2003]. High exposures to $\mathrm{CO}$ and $\mathrm{CO}_{2}$ can cause headache, dizziness, fatigue, nausea, altered mentation, rapid breathing, impaired consciousness, coma, and death [Newton 2002; Nishimura et al. 2003; Langford 2005; CDC 2013; Raffel and Thompson 2013; Rose et al. 2017]. Occupational exposure limits for $\mathrm{CO}$ and $\mathrm{CO}_{2}$ are listed in Table 1 .

\section{Exposure Limits}

We use mandatory (legally enforceable) and recommended occupational exposure limits (OELs) when evaluating workplace hazards. OELs have been developed by federal agencies and safety and health organizations to prevent adverse health effects from workplace exposures.

Occupational Safety and Health Administration (OSHA) [Mandatory]

The U.S. Department of Labor's OSHA permissible exposure limits (PELs) are legal limits enforceable in workplaces covered under the Occupational Safety and Health Act. OSHA PELs represent the legal maximum for a TWA exposure to a physical or chemical agent over a work shift [OSHA 2017]. OSHA short-term exposure limits (STELs) are the legal maximum average exposure for a 15-minute time period. Some chemicals also have an OSHA ceiling value that represent levels that must not be exceeded at any time. Currently, there are no PELs for diacetyl, 2,3-pentanedione or 2,3-hexanedione. For substances for which an OSHA PEL has not been issued, violation of the OSHA General Duty Clause can be considered using available occupational exposure references and recommendations [OSHA 1993; OSHA 2003], such as the American Conference of Governmental Industrial Hygienists (ACGIH) Threshold Limit Values $\left(\mathrm{TLVS}^{\circledR}\right)$ and NIOSH RELs.

American Conference of Governmental Industrial Hygienists (ACGIH) [Recommended] ACGIH is a professional, not-for-profit scientific association that reviews existing published, peer-reviewed scientific literature and publishes recommendations for levels of substances in air based on an 8-hour workday and 40-hour workweek. These recommendations are called TLVs [ACGIH 2017a]. ACGIH TLVs are not standards; they are health-based 
guidelines derived from scientific and toxicological information. ACGIH provides TLV-TWA guidelines that are levels that should not be exceeded during any 8-hour workday of a 40hour workweek. ACGIH also provides TLV-STEL guidelines which are 15-minute exposure levels that should not be exceeded during a workday. Exposures above the TLV-TWA but less than the TLV-STEL should be (1) less than 15 minutes, (2) occur no more than four times a day, and (3) be at least 60 minutes between exposures [ACGIH 2017a]. Additionally, ACGIH provides TLV-Ceiling values which are levels that should not be exceeded at any time during a work shift. The ACGIH TLV-TWA for diacetyl is $10 \mathrm{ppb}$. The TLV-STEL for diacetyl is 20 ppb. Currently, there is no TLV-TWA or TLV-STEL for 2,3-pentanedione. ACGIH has placed 2,3-pentanedione on the 2017 list of Chemical Substances and Other Issues Under Study [ACGIH 2017b].

National Institute for Occupational Safety and Health (NIOSH) [Recommended] NIOSH provides RELs as TWA concentrations that should not be exceeded over an 8 or 10-hour work shift, during a 40-hour workweek [NIOSH 2010]. RELs are intended to be protective over a 45-year working lifetime. NIOSH also provides STELs which are 15-minute TWA exposures that should not be exceeded at any time during a workday [NIOSH 2010]. Some chemicals have ceiling values which are concentrations that should not be exceeded at any time [NIOSH 2010]. For some chemicals, NIOSH has Immediately Dangerous to Life or Health (IDLH) values. An IDLH value is a concentration of an air contaminant that can cause death or immediate or delayed permanent adverse health effects, or prevent escape from such an environment. Currently, NIOSH has RELs and STELs for diacetyl and 2,3-pentanedione. NIOSH does not have a REL or a STEL for 2,3-hexanedione. NIOSH does not have ceiling limits or IDLH values for diacetyl, 2,3-pentanedione, or 2,3-hexanedione.

For diacetyl and 2,3-pentanedione, the NIOSH RELs are $5.0 \mathrm{ppb}$ and $9.3 \mathrm{ppb}$, respectively, as a TWA for up to an 8-hour workday during a 40-hour workweek (Table 1). The NIOSH STELs are $25 \mathrm{ppb}$ for diacetyl and $31 \mathrm{ppb}$ for 2,3-pentanedione [NIOSH 2016]. The NIOSH exposure standards do not differentiate between natural and synthetic chemical origin of diacetyl or 2,3-pentanedione. Although the NIOSH exposure limit for 2,3-pentanedione is above that of diacetyl, 2,3-pentanedione has been shown to be as hazardous as diacetyl [Hubbs et al. 2012; Morgan et al. 2012]. The NIOSH REL is higher for 2,3-pentanedione than for diacetyl largely because analytic measures were not available in a validated OSHA method to detect 2,3-pentanedione at lower levels. The hazard potential probably increases when these chemicals occur in combination with each other; having exposure to chemicals with the same functional alpha-diketone group and effect on the same system or organ (e.g., lungs) can result in additive effects [ACGIH 2017a]. In addition to the REL, NIOSH also recommends an action level for diacetyl of $2.6 \mathrm{ppb}$ to be used with exposure monitoring in an effort to ensure employee exposures are routinely below the diacetyl REL. When exposures exceed the action level, employers should take corrective action (i.e., determine the source of exposure, identify methods for controlling exposure) to ensure that exposures are maintained below the NIOSH REL for diacetyl [NIOSH 2016]. 
Table 1. Personal exposure limits for compounds sampled for during the NIOSH survey, April 2016.

\begin{tabular}{|l|c|c|c|c|c|c|}
\hline \multirow{2}{*}{ Compound } & OSHA $^{*}$ & \multicolumn{2}{|c|}{ ACGIH } & \multicolumn{3}{c|}{ NIOSH } \\
\cline { 2 - 7 } & PEL & TLV & STEL & REL & STEL & IDLH \\
\hline Diacetyl & - & $10 \mathrm{ppb}$ & $20 \mathrm{ppb}$ & $5.0 \mathrm{ppb}^{\dagger}$ & $25 \mathrm{ppb}$ & - \\
\hline 2,3-Pentanedione & - & - & - & $9.3 \mathrm{ppb}^{\dagger}$ & $31 \mathrm{ppb}$ & - \\
\hline 2,3-Hexanedione & - & - & - & - & - & - \\
\hline Carbon dioxide & $5,000 \mathrm{ppm}$ & $5,000 \mathrm{ppm}$ & $30,000 \mathrm{ppm}$ & $5,000 \mathrm{ppm}$ & $30,000 \mathrm{ppm}$ & $40,000 \mathrm{ppm}$ \\
\hline $\begin{array}{l}\text { Carbon } \\
\text { monoxide }\end{array}$ & $50 \mathrm{ppm}$ & $25 \mathrm{ppm}$ & - & $35 \mathrm{ppm}$ & $\begin{array}{c}200 \mathrm{ppm} \\
\text { (ceiling limit) }\end{array}$ & $1,200 \mathrm{ppm}$ \\
\hline
\end{tabular}

Note: OSHA=Occupational Safety and Health Administration; ACGIH=American Conference of Governmental Industrial Hygienists; NIOSH=National Institute for Occupational Safety and Health; $P E L=$ ermissible exposure limit; $T L V=$ threshold limit value; $S T E L=$ short-term exposure limit; $R E L=$ recommended exposure limit; IDLH=immediately dangerous to life or health; $p p b=$ parts per billion; ppm=parts per million; "- " =no exposure limit available.

"There are no OSHA STEL values for the compounds in the table.

The NIOSH RELs for diacetyl and 2,3-pentanedione are time-weighted averages for up to 8-hour day, during a 40-hour workweek.

§OSHA and NIOSH limits are designed for occupational exposure measurements in manufacturing and other trades that have potential sources of carbon dioxide or carbon monoxide (e.g., welding, vehicle exhaust, diesel engine exhaust). Typical levels of carbon monoxide in offices are $0-5 \mathrm{ppm}$. In office settings, carbon dioxide generally should not be greater than $700 \mathrm{ppm}$ above outdoor carbon dioxide levels; this typically corresponds to indoor concentrations below $1,200 \mathrm{ppm}$.

"This is the NIOSH ceiling exposure limit for carbon monoxide. A ceiling concentration should not be exceeded at any time.

\section{Obliterative Bronchiolitis}

Obliterative bronchiolitis is a serious, often disabling, lung disease that involves scarring of the very small airways (i.e., bronchioles). Symptoms of this disease may include cough, shortness of breath on exertion, and/or wheeze, that do not typically improve away from work [NIOSH 2012]. Occupational obliterative bronchiolitis has been identified in flavoring manufacturing workers and microwave popcorn workers who worked with flavoring chemicals or butter flavorings [Kreiss 2013; Kim et al. 2010; Kanwal et al. 2006]. It has also been identified in employees at a coffee roasting and packaging facility that produced unflavored and flavored coffee [CDC 2013b]. A NIOSH health hazard evaluation at that facility found diacetyl and 2,3-pentanedione concentrations in the air that were elevated and identified three sources: 1) flavoring chemicals added to roasted coffee beans in the flavoring area; 2) grinding unflavored roasted coffee beans and packaging unflavored ground and whole bean roasted coffee in a distinct area of the facility, and 3) storing roasted coffee in hoppers, on a mezzanine above the grinding/packaging process, to off-gas [Duling et al. 2016]. At the time of the health hazard evaluation, workers had excess shortness of breath and obstruction on spirometry, both consistent with undiagnosed lung disease. Respiratory illness was associated with exposure and not limited to the flavoring areas [Bailey et al. 2015]. However, all workers who were diagnosed with obliterative bronchiolitis had worked in the flavoring area. To date, no cases of obliterative bronchiolitis have been reported in workers at coffee roasting and packaging facilities that produce only unflavored coffee. 


\section{Work-related Asthma}

Work-related asthma refers to asthma that is brought on by ("occupational asthma") or made worse by ("work-exacerbated asthma" or "work-aggravated asthma") workplace exposures [Tarlo 2016; Tarlo and Lemiere 2014; OSHA 2014; Henneberger et al. 2011; NIOSH 2017]. It includes asthma due to sensitizers, which cause disease through immune (allergic) mechanisms, and asthma due to irritants, which cause disease through non-immune mechanisms. Symptoms of work-related asthma include episodic shortness of breath, cough, wheeze, and chest tightness. The symptoms may begin early in a work shift, towards the end of a shift, or hours after a shift. They generally, but do not always, improve or remit during periods away from work, such as on weekends or holidays.

Green and roasted coffee dust and castor beans (from cross-contamination of bags used to transport coffee) are known risk factors for occupational asthma [Figley and Rawling 1950; Karr et al. 1978; Zuskin et al. 1979, 1985; Thomas et al. 1991]. Persons who become sensitized (develop an immune reaction) to coffee dust can subsequently react to relatively low concentrations in the air. Others may experience irritant-type symptoms from exposure to coffee dust [Oldenburg et al. 2009].

\section{Process Description}

\section{Coffee Roasting and Packaging Facility}

The coffee roasting and packaging facility had been at the current location since September 2014. The facility was in a shared building and was approximately 5,300 square feet $\left(\mathrm{ft}^{2}\right)$ that included production space, a quality control (QC) café, office spaces, and storage. The production area was approximately $3,100 \mathrm{ft}^{2}$ and the QC café area was roughly $490 \mathrm{ft}^{2}$. Both spaces had a ceiling height of nearly 20 feet. The office spaces combined for nearly $550 \mathrm{ft}^{2}$ with a ceiling height of 11 feet. There were thirteen current employees at the time of the NIOSH survey. Six employees were involved in production tasks including roasting, weighing and packaging, grinding, and QC. The other seven employees were involved in various administrative tasks including bookkeeping, sales, marketing, and reception. At the time of the NIOSH visit in March 2016, the process for roasting coffee, from receiving green beans to distributing finished product was as described below.

Green beans were received in burlap bags from around the world including, but not limited to, Colombia, Mexico, Bolivia, Peru, Ecuador, Ethiopia, and Uganda. Upon arrival at the facility, burlap bags of green beans were stored on wooden pallets in the green bean storage area until they were dumped into large storage bins. To prepare a batch for roasting, a roaster operator filled 5-gallon buckets with green beans from the storage bins. Each bin was equipped with a dispensing station through the wall of the green bean storage area. Each station had a slot that was opened and closed with a sliding door, and the doors were all equipped with an electrical switch that turned on a dust capture system when the slot was opened. The dust capture system consisted of round, galvanized ductwork from each dispensing station attached to a Shop Fox (Woodstock International, Inc., Bellingham, WA) W1727 1HP Dust Collector. This system was installed to capture any dust generated during the dispensing of green beans. 
The 5-gallon buckets sat on a scale and were filled with green beans until they reached the proper weight for a given roast. The roaster operator manually dumped the buckets of green beans into the hopper on top of a Probat (PROBAT-Werke von Gimborn Maschinenfabrik $\mathrm{GmbH}$, Emmerich am Rhein, Germany) Model UG30 Roaster, produced in the early-1930s. The roaster was capable of roasting up to 66 pounds (30 kilograms) of coffee per roast, but a 55-pound load was more typical. To initiate the roast, the roaster operator manually released the green beans from the hopper into the roasting drum where they were heated at a specific temperature and time period for the desired roast. Time and temperature varied between different types of roasts. At the end of each roast cycle, the roaster operator manually opened a door at the bottom of the roasting drum to empty the roasted beans into the cooling drum, where they were automatically mixed by an agitator to accelerate cooling. The cooling drum utilized a downdraft exhaust system that drew air over the roasted beans and down into the cooling drum to accelerate cooling. The downdraft system exhausted through the roof. The roaster operator monitored the roasting equipment carefully throughout the roasting and cooling process. After adequate cooling, the roasted beans were emptied from the cooling drum into plastic storage containers. The roaster operator then manually moved the containers to the roasted bean storage area.

To package roasted coffee beans, an employee used a Logical Machines (Charlotte, VT) Weigh-Fill System with an added pneumatic feeder to automatically load the roasted beans into the hopper of the machine. A flexible vacuum hose was inserted into a plastic storage container that held the roasted beans. The pneumatic system transferred beans from the container into the weigh-fill hopper to fill 12 ounce, 2 kilogram, and 5 pound bags with whole beans.

For ground coffee, whole roasted beans were loaded into appropriate bags using the weighfill system. The beans from the bag were then dumped into a Mahlkönig (Mahlkönig GmbH \& Co. KG, Hamburg, Germany) TTA6S13FC grinder where they were ground and dispensed back into the bag for packaging. The grinder could be adjusted for type of grind (coarse, medium, or fine). After all packages were filled with either whole bean or ground coffee, they were heat sealed and placed on shelves or immediately in shipping boxes for shipment or local delivery. Beans were generally packaged within 12 hours of roasting, often sooner than that.

\section{Quality Control}

Upon receipt, green beans were roasted in an early-1900s Jabez Burns \& Sons (New York, NY) S/N 12X53 dual-barrel sample roaster and profiled by an employee to determine the best roast (roast temperature and time) for the beans. The company took measures to ensure the quality of their roasted coffees. After each roast, the roaster operator ground a small sample using a Mahlkönig K32S10 grinder and placed the ground coffee into a Javalytics (Madison Instruments, Inc., Middleton, WI) Model JAV-RDA-DN Degree of Roast Analyzer to analyze the roast darkness. The facility also had a QC café where roasted beans, brews, and espressos could be prepared and assessed. The company also offered training to baristas at other locations that brewed and served their coffees. 


\section{Personal Protective Equipment}

Employees were not required to wear a company uniform or protective clothing. However, we did observe one employee wearing respiratory protection for dust while dumping green beans from burlap bags into the large green bean storage bins. Hearing protection was also used by some employees during their work activities.

\section{Café}

At the time of the NIOSH visit in March 2016, the café served coffee drinks, tea, cookies, sandwiches, granola and yogurt. In existence since December 19, 2015, the café was open seven days a week. In addition to the owner, there were 12 part-time employees. It was roughly $1,900 \mathrm{ft}^{2}$ and had seating for 51 patrons. The serving area of the café was equipped with three coffee grinders; two of which were used for espresso and the third for general coffee grinding. The café also was equipped with one espresso machine with four brew elements and two steam elements, and a one-gallon twin coffee brewer system. There was a small kitchen area in the rear of the space used to prepare food items.

\section{Methods}

Upon arrival at the coffee roasting and packaging facility and the separate, associated café, we held an opening meeting with management and employees, collected bulk samples and air samples, and performed a ventilation assessment. At the conclusion of our site visits, we held brief closing meetings with management. Separate medical surveys were also conducted at each location. An interim report with preliminary recommendations was sent to each facility following our visit.

We had the following objectives for the health hazard evaluation:

1. Measure employees exposure to diacetyl, 2,3-pentanedione, and 2,3-hexanedione during coffee roasting and packaging and café activities;

2. Identify process areas or work tasks associated with emissions of diacetyl, 2,3-pentanedione, and 2,3-hexanedione;

3. Measure levels of $\mathrm{CO}$ and $\mathrm{CO}_{2}$ in areas of the coffee roasting and packaging facility and café;

4. Measure pre- and post-shift air concentrations of diacetyl, 2,3-pentanedione, and 2,3-hexanedione to determine if concentrations change over the work shift;

5. Assess the ventilation systems and their effect on exposure levels;

6. Determine prevalence of mucous membrane, respiratory, and systemic symptoms among employees and portion of those symptoms that were work-related or aggravated by work;

7. Determine if employees had abnormal lung function tests; and

8. Compare employees' prevalence of lower respiratory symptoms and healthcare provider-diagnosed asthma to expected levels based on general population values. 


\section{Industrial Hygiene Assessment}

\section{Sampling Times for Alpha-Diketones}

We designed the sampling strategy to assess full-shift exposures and to identify tasks and processes that were the greatest contributors to worker exposure to alpha-diketones. Sampling was conducted over multiple days at the roasting and packaging facility and on a single day at the café. For diacetyl, 2,3-pentanedione, and 2,3-hexanedione, the air samples were collected over seconds, minutes, and hours. Samples collected over hours can help determine average concentrations that can be compared to the NIOSH RELs for diacetyl and 2,3-pentanedione. These average concentrations do not tell us about short-term peak exposures that could be relevant to respiratory health, particularly when tasks are repeated multiple times per day. Therefore, during particular tasks, we collected air samples over several minutes; these samples can provide information about which tasks have relatively higher exposures. To help identify point sources of chemicals, we also performed real-time sampling and collected instantaneous samples over seconds.

\section{Air Sampling and Analysis Using Modified Occupational Safety and Health Administration (OSHA) Methods 1013/1016}

We collected personal and area air samples for diacetyl, 2,3-pentanedione, and 2,3-hexanedione on silica gel sorbent tubes throughout the facility. The samples were collected and analyzed according to the modified OSHA sampling and analytical Methods 1013/1016 [OSHA 2008; OSHA 2010; LeBouf and Simmons 2017]. In accordance with the two methods, two glass silica gel sorbent tubes were connected by a piece of tubing and inserted into a protective, light-blocking cover. The tubes were connected in series to a sampling pump pulling air through the tubes at a flow rate of 50 milliliters per minute ( $\mathrm{mL} / \mathrm{min})$. The sampling setup was attached to an employee's breathing zone or in an area basket at various places throughout the facility. For full-shift sampling, we collected two consecutive 3-hour samples and calculated the TWA concentration from the two samples, assuming that the total 6-hour monitoring results reflected a full work shift (8-hour) TWA exposure. Although this may introduce some error, it is a conservative approach that is more protective of employees than the alternative assumption of no exposure during the last two hours of the shift. We refer to these samples as "full-shift samples" throughout this report. We also collected short-term, task-based samples in the same manner, but the sampling pump flow rate was $200 \mathrm{~mL} / \mathrm{min}$ as detailed in OSHA Methods 1013 and 1016 [OSHA 2008; 2010]. Sampling times were dependent on the duration of the task being performed.

Analyses of the samples were performed at the NIOSH Respiratory Health Division's Organics Laboratory. Briefly, the samples were extracted for 1 hour in 95\% ethanol:5\% water containing 3-pentanone as an internal standard. Samples were analyzed using an Agilent 7890/7001 gas chromatograph/mass spectrometer system operated in selected ion monitoring mode for increased sensitivity compared to the traditional flame ionization detector used in OSHA Methods 1013 and 1016 [LeBouf and Simmons 2017].

A limit of detection (LOD) is the lowest mass that an instrument can detect above background and is a criterion used to determine whether to report a result from a sample. 
The LODs were 0.010 micrograms per sample ( $\mu \mathrm{g} / \mathrm{sample}$ ) for diacetyl, $0.012 \mu \mathrm{g} / \mathrm{sample}$ for 2,3-pentanedione, and $0.020 \mu \mathrm{g} / \mathrm{sample}$ for 2,3-hexanedione. For a typical full-shift TWA air sample, these equate to $0.32 \mathrm{ppb}$ for diacetyl, $0.33 \mathrm{ppb}$ for 2,3-pentanedione, and 0.48 ppb for 2,3-hexanedione. The LODs for task samples vary because of differing air volumes collected while sampling specific tasks and are higher than typical LOD values. When the values presented in the report are from samples below the LOD they are denoted by a "<" symbol.

\section{Air Sampling and Analysis Using Evacuated Canisters}

We collected instantaneous, personal, task-based and source-based air samples for airborne alpha-diketones using evacuated canisters during the industrial hygiene surveys. We also collected instantaneous area air samples before and after the work shift to determine if air concentrations of alpha-diketones varied over a work shift. The canister sampling setup consisted of a 450-mL (milliliter) evacuated canister equipped with an instantaneous flowcontroller (less than 30 seconds). Instantaneous samples were taken by opening the evacuated canister to grab a sample of air in order to determine possible peak exposures and alphadiketone levels at point sources. For personal task-based samples, the canister was held in the worker's breathing zone to mimic their personal instantaneous exposure. For sourcebased samples, the canister was held at a process exposure point of interest to measure concentrations released by the process. Source-based samples help identify process locations that may emit high levels of alpha-diketones, but they do not necessarily represent worker exposures to the same airborne concentrations.

The canister air samples were analyzed using a pre-concentrator/gas chromatograph/ mass spectrometer system pursuant to a published method validation study [LeBouf et al. 2012], with the following modifications: the pre-concentrator was a Model 7200 (Entech Instruments, Inc.), and three additional analyte compounds, diacetyl, 2,3-pentanedione, and 2,3-hexanedione, were included. At present, this canister method is partially validated and being reviewed for incorporation into the NIOSH Manual of Analytical Methods. The typical LOD was $0.39 \mathrm{ppb}$ for diacetyl, $0.54 \mathrm{ppb}$ for 2,3-pentanedione, and $0.96 \mathrm{ppb}$ for 2,3-hexanedione based on a 1.5-times dilution factor, which is typical for restricted flow controller samples. However, LODs are dependent on canister pressure and may be higher or lower than typical LOD values.

\section{Bulk Sampling and Headspace Analysis}

We used 50-mL sterile polypropylene centrifuge tubes to collect approximately $40-\mathrm{mL}$ bulk samples of green coffee beans and whole bean roasted coffee. For headspace analysis of alpha-diketones, we transferred 1 gram of solid bulk material into a sealed $40-\mathrm{mL}$ amber volatile organic analysis vial and let it rest for 24 hours at room temperature $\left(70^{\circ} \mathrm{F}\right)$ in the laboratory. Then $2 \mathrm{~mL}$ of headspace air was transferred to a $450-\mathrm{mL}$ canister and pressurized to approximately 1.5 times atmospheric pressure. Using the canister analysis system, the concentrations were calculated in ppb of analytes in the headspace as an indicator of emission potential. 


\section{Real-time (Continuous) Air Sampling}

We used RAE Systems (San Jose, CA) ppbRAE 3000 (Model \#PGM-7340) monitors to measure levels of total volatile organic compounds in the air. Two ppbRAE 3000 monitors (RAE Systems, San Jose, CA) were used to measure levels of total VOCs in the air near potential sources. The ppbRAE has a non-specific photoionization detector that responds to chemicals with ionization potentials below the energy of the lamp. This sampling was conducted to identify areas where coffee could be releasing TVOCs. Real-time monitoring of temperature, relative humidity, $\mathrm{CO}_{2}$, and $\mathrm{CO}$ was performed using VelociCalc Model 9555-X Multi-Function Ventilation Meters equipped with a Model 982 IAQ probe (TSI Incorporated, Shoreview, MN).

\section{Ventilation Assessment}

We did a visual and physical assessment of all ventilation components at each facility. Physical measurements of each facility were taken with a Model DISTO E7100i laser-tape measure (Leica Geosystems AG, Heerbrugg, Switzerland). Ventilation measurements were taken using either a Model EBT731 Balometer Air Balancing Instrument (Alnor Products, TSI Incorporated, Shoreview, MN) or a Model RVA501 Rotating-Vane Air Velocity Meter (Alnor Products, TSI Incorporated, Shoreview, MN). Information on existing ventilation equipment, including make, model, and specified performance levels, was also collected. When appropriate, differential pressure measurements between adjacent spaces were taken under various ventilation scenarios using an Energy Conservatory (Minneapolis, MN) DG500 Pressure Gauge.

\section{Medical Survey}

\section{Participants}

We invited all current employees at the café to participate in the medical survey on March 12, 2016. The medical survey was conducted at a nearby hotel within walking distance from the café. We invited all current employees at the coffee roasting and packaging facility to participate in the medical survey at the workplace on March 17, 2016. Participation was voluntary; written informed consent was obtained from each participant before testing. The survey included, in the order performed, a medical and work history questionnaire, quantification of exhaled nitric oxide, impulse oscillometry, spirometry, and if indicated the administration of a bronchodilator with repeat impulse oscillometry and spirometry. We mailed participants their individual reports explaining their breathing test results and recommended each participant provide the information to their personal physician.

\section{Questionnaire}

We used an interviewer-administered computerized questionnaire to ascertain symptoms and diagnoses, work history at this coffee roasting and packaging facility and other coffee or flavoring companies, and cigarette smoking history. Questions on respiratory health were derived from five standardized questionnaires, the European Community Respiratory Health Survey [Burney et al. 1994; ECRHS 2014], the American Thoracic Society adult respiratory questionnaire (ATS-DLD-78) [Ferris 1978], the International Union Against Tuberculosis and Lung Disease [Burney and Chinn 1987; Burney et al. 1989], and the Third National Health and Nutrition Examination Survey (NHANES III) [CDC 1996] and NHANES 2007- 
-2012 questionnaires [CDC 2018]. Some of the questions appeared on more than one of the standardized questionnaires. We also supplemented our questionnaire with additional respiratory and systemic symptom questions.

\section{Spirometry}

The purpose of the spirometry test was to determine a person's ability to move air out of their lungs. Test results were compared to expected normal values. The test included three measurements or calculations: 1) forced vital capacity (FVC), (the total amount of air the participant can forcefully blow out after taking a deep breath), 2) $\mathrm{FEV}_{1}$ (the amount of air that the participant can blow out in the first second of exhaling), and 3) the ratio of $\mathrm{FEV}_{1}$ to FVC. We used American Thoracic Society criteria for acceptability and repeatability [Miller et al. 2005].

We used a volume spirometer (dry rolling seal spirometer) to measure exhaled air volume and flow rates. We used equations for predicted values and lower limits of normal derived from NHANES III data to define abnormal spirometry [Hankinson et al. 1999]. We defined obstruction as an $\mathrm{FEV}_{1} / \mathrm{FVC}$ ratio less than the lower limit of normal with $\mathrm{FEV}_{1}$ less than the lower limit of normal; restriction as a normal $\mathrm{FEV}_{1} / \mathrm{FVC}$ ratio with $\mathrm{FVC}$ less than the lower limit of normal; and mixed obstruction and restriction as having $\mathrm{FEV}_{1}, \mathrm{FVC}$, and $\mathrm{FEV}_{1} / \mathrm{FVC}$ ratio all less than the lower limit of normal. We used the $\mathrm{FEV}_{1}$ percent predicted to categorize such abnormalities as mild, moderate, moderately severe, severe, or very severe [Pellegrino et al. 2005].

\section{Impulse Oscillometry}

Many occupational lung diseases (e.g., chronic obstructive pulmonary disease (COPD), asthma) involve the small airways; however, this part of the lung is difficult to evaluate noninvasively. Oscillometry is a helpful technology to understand the effects of occupational exposures on the small airways. There are no contraindications to the test as this test is conducted using regular breathing and does not require a forceful exhalation [Smith et al. 2005]. Spirometry can be normal despite respiratory symptoms or evidence of small airways disease on lung biopsy [King et al. 2011; Oppenheimer et al. 2007]; therefore, oscillometry results complement spirometry and can be used when spirometry is not possible because of a contraindication.

We used an impulse oscillometry machine (CareFusion Corp., San Diego, CA) to measure resistance (R), the energy required to propagate the pressure wave through the airways, and reactance $(\mathrm{X})$, which reflects the viscoelastic properties of the respiratory system. The impulse oscillometry testing machine sends sound waves called pressure oscillations at different frequencies (e.g., 5 Hertz and 20 Hertz) into the airways to measure how airways respond to these small pressures. The test calculates 1$)$ the airway resistance at different frequencies including 5 Hertz (R5) and 20 Hertz (R20), and the difference between R5 and R20 (DR5-R20); 2) the reactance at different frequencies including 5 Hertz (X5); 3) resonant frequency (Fres) which is the frequency where there is no airway reactance; and 4) the total reactance (AX) at all frequencies between 5 Hertz and the Fres. The predicted values for $\mathrm{R}$ and $\mathrm{X}$ were based on sex and age according to reference values recommended 
by the manufacturer [Vogel and Smidt 1994]. R5 was considered abnormal (elevated) if the measured value was equal to or greater than 140 percent of the predicted R5. X5 was considered abnormal (decreased) if the value of the predicted X5 minus measured X5 was equal to or greater than 0.15 kilopascals per liter per second $(\mathrm{kPa} /(\mathrm{L} / \mathrm{s}))$. DR5-R20 values greater than 30\% were considered abnormal and evidence of frequency dependence [Smith 2015]. We interpreted the test as normal if both the R5 and X5 were normal [Smith 2015]. We defined possible large (central) airways abnormality as a normal X5 and elevated R5 with no evidence of frequency dependence. We defined a possible small airways abnormality if there was evidence of frequency dependence and/or a decreased X 5 with or without an elevated R5. We defined possible combined small (peripheral) and large (central airways) abnormality as a decreased X5 and elevated R5 with no evidence of frequency dependence.

\section{Bronchodilator Reversibility Testing for Impulse Oscillometry and Spirometry}

If a participant had abnormal impulse oscillometry or spirometry, we repeated both tests after the participant received a bronchodilator inhaler medication (i.e., albuterol), which can open the airways in some individuals (e.g., asthmatics). For oscillometry, we defined reversibility (improvement) after bronchodilator administration as a decrease of at least $20 \%$ of either Fres or R5 or a decrease of $40 \%$ for AX. For spirometry, we defined reversibility (improvement) as increases of at least $12 \%$ and $200 \mathrm{~mL}$ for either $\mathrm{FEV}_{1}$ or $\mathrm{FVC}$ after bronchodilator administration.

Fractional Exhaled Nitric Oxide (FeNO)

We used the NIOX MINO ${ }^{\circledR}$ device (Aerocrine Inc., Morrisville, NC) to measure the amount of nitric oxide in the air the participant breathed out. Nitric oxide is a gas that is produced by the airways, and elevated levels can be a sign of eosinophilic airway inflammation in asthma [Dweik et al. 2011]. In adults, fractional nitric oxide concentration in exhaled breath levels above $50 \mathrm{ppb}$ are considered elevated. In adults with asthma, elevated levels may indicate that their asthma is uncontrolled [Dweik et al. 2011].

\section{Statistical Analysis}

Industrial Hygiene Survey and Ventilation Assessment We performed analyses using Excel (Microsoft ${ }^{\circledR}$, Redmond, WA) and SAS version 9.3 (SAS Institute Inc., Cary, NC). We created summary statistics by work area location, job title, and task. When the values presented in the report are from samples below the LOD they are denoted by a " $<$ " symbol.

\section{Medical Survey}

We calculated frequencies and standardized morbidity ratios (SMRs) and their associated 95\% confidence intervals (CIs) using SAS version 9.3 (Cary, NC). The SMRs compared prevalences of symptoms among participants to expected prevalences of a sample of the general population reflected in the NHANES III (1988-1994) and NHANES 2007-2012, adjusting for sex, race/ethnicity, age (less than 40 years old or 40 years or greater), and cigarette smoking categories (ever/never). For comparisons to the U.S. population, we used the most recent NHANES survey available for the specific comparisons. The small number 
of participants limits the conclusions that can be drawn from these analyses. Nonetheless, we report these results for the medical participants at the coffee roasting and packaging facility to provide some context for how commonly these symptoms and diagnoses are reported by adults in the general population.

\section{Results}

Employees that participated in air sampling were given the opportunity to request their individual air sampling results. All results from the industrial hygiene and medical surveys at the coffee roasting and packaging facility are presented in Appendix A. Appendix B includes all of the industrial hygiene and medical survey results from the café. This section provides a summary of the results presented in those appendices.

\section{Coffee Roasting and Packaging Facility}

\section{Industrial Hygiene Survey at Coffee Roasting and Packaging Facility}

\section{Personal and Area Full-shift Air Sampling}

OSHA Methods 1013/1016

Table A1 presents the personal and area full-shift air sampling results from our visit to the coffee roasting and packaging facility in March 2016. We collected 11 personal full-shift air samples from seven total employees over two days. During that time, we also collected 17 area full-shift air samples. Personal samples collected on employees in the production area and in QC and roasting generally had higher exposures to diacetyl (range of 1.5 ppb to 4.7 $\mathrm{ppb}$ ) and 2,3-pentanedione (1.1 ppb - 3.9 ppb). However, all personal air samples were below the NIOSH REL for diacetyl of $5.0 \mathrm{ppb}$ and below the NIOSH REL for 2,3-pentanedione of $9.3 \mathrm{ppb}$. All 11 personal samples collected were below the LOD for 2,3-hexanedione.

Area sampling results showed a similar pattern to the personal sampling results in that samples from the production area generally had higher concentrations of diacetyl $(0.6 \mathrm{ppb}-$ $4.3 \mathrm{ppb})$ and 2,3-pentanedione $(0.5 \mathrm{ppb}-3.6 \mathrm{ppb})$ than in other areas of the facility. All 17 area samples were below the LOD for 2,3-hexanedione.

\section{Personal Task-based Air Sampling}

OSHA Methods 1013/1016

Table A2 presents the OSHA Methods 1013/1016 personal task-based air concentrations from our visit to the roasting and packaging facility in March 2016, by individual task. Importantly, tasks associated with coffee roasting, grinding, and packaging are varied and, as such, the duration also varies. We collected 25 personal task-based air samples and the sample duration ranged from seven to 17 minutes. Fifteen of the tasks sampled lasted for 15 minutes, allowing for their results to be compared directly with the NIOSH STELs for diacetyl (25 ppb) and 2,3-pentanedione (31 ppb).

An employee that ground coffee beans had the highest 15-minute diacetyl (9.4 ppb) and 2,3-pentanedione (9.9 ppb) exposures, but all 15-minute personal task-based samples were 
well below the NIOSH STEL for diacetyl (25 ppb) and 2,3-pentanedione (31 ppb). While not directly comparable to the STEL, the ten other task-based samples that lasted more or less than 15-minutes were also well below the STELs. All samples were below the LOD for 2,3-hexanedione.

\section{Instantaneous Evacuated Canisters}

Table A3 presents the personal task-based air concentrations from the evacuated canister sampling from our March 2016 visit to the roasting and packaging facility. All evacuated canisters were equipped with an instantaneous flow controller with a sample duration of approximately 30 seconds. Because of the very short duration of the samples, results should not be compared with 15-minute STELs. We collected 18 personal task-based canister air samples. Ten of the 18 samples were collected in the breathing zone of employees grinding coffee for packaging. Sample concentrations ranged from $5.5 \mathrm{ppb}-$ $458 \mathrm{ppb}$ for diacetyl, $3.9 \mathrm{ppb}-431 \mathrm{ppb}$ for 2,3-pentanedione, and from below the LOD to $17.4 \mathrm{ppb}$ for 2,3-hexanedione. Four additional samples were taken in the breathing zone of the roaster operator grinding small coffee samples to measure roast depth. Those instantaneous exposures varied from $0.3 \mathrm{ppb}-66.1 \mathrm{ppb}$ for diacetyl, $0.4 \mathrm{ppb}-45.8 \mathrm{ppb}$ for 2,3-pentanedione, and below the LOD to $2.7 \mathrm{ppb}$ for 2,3-hexanedione. Two samples were collected as an employee packaged coffee with the auto-fill machine, but the concentrations of the alpha-diketones were relatively low (5.5 ppb and $7.2 \mathrm{ppb}$ for diacetyl, $4.7 \mathrm{ppb}$ and $3.3 \mathrm{ppb}$ for 2,3-pentanedione, and $1.1 \mathrm{ppb}$ and less than $1.0 \mathrm{ppb}$ for 2,3-hexanedione). The same is true for a sample collected as an employee opened a bin of roasted coffee beans (14.6 ppb diacetyl; 12.9 ppb 2,3-pentanedione, and less than 1.0 ppb 2,3-hexanedione) and also transferred roasted beans from the roaster cooling bin into a storage container $(2.4 \mathrm{ppb}$ diacetyl; 2.4 ppb 2,3-pentanedione, and less than 1.0 ppb 2,3-hexanedione).

\section{Source-based Air Sampling}

Instantaneous Evacuated Canisters

Table A4 presents instantaneous source air sampling results using evacuated canisters from our March 2016 visit to the roasting and packaging facility. We collected 17 source air samples using instantaneous evacuated canisters. The highest concentrations were measured in a sample taken at the mouth of the sample roaster when roasting beans reached the point of "first crack." Measured concentrations in this sample were $708 \mathrm{ppb}$ of diacetyl, $502 \mathrm{ppb}$ of 2,3-pentanedione, and $12.8 \mathrm{ppb}$ of 2,3-hexanedione. A second sample taken at the sample roaster as beans were dumped into the cooling tray showed concentrations of all alphadiketones at or below $6 \mathrm{ppb}$. After the sample roaster, the highest source concentrations were associated with the main roaster and quality control activities using ground coffee. Pouring hot water into ground coffee for cupping and grinding coffee produced the highest source exposures associated with quality control. The concentrations in three samples collected at the main roaster drum door opening as beans were dumped into the cooling bin ranged from $15.4 \mathrm{ppb}-74.0 \mathrm{ppb}$ for diacetyl, 8.7 ppb - 39.0 ppb for 2,3-pentanedione, and 2.1 $\mathrm{ppb}-20.3 \mathrm{ppb}$ for 2,3-hexanedione. Three samples collected above the roaster cooling bin as the beans cooled showed the lowest concentrations with diacetyl from $1.8 \mathrm{ppb}-2.3 \mathrm{ppb}$, 2,3-pentanedione from $1.3 \mathrm{ppb}-2.3 \mathrm{ppb}$, and 2,3-hexanedione ranging from below the LOD to $1.2 \mathrm{ppb}$. 


\section{Background Pre- and Post-shift Instantaneous Evacuated Canister Sampling}

Table A5 presents the instantaneous evacuated canister pre- and post-shift background air sampling results from our visit. Both diacetyl and 2,3-pentanedione air concentrations increased over the course of the work day. The pre-shift diacetyl air concentration was $0.9 \mathrm{ppb}$ and post-shift air concentration was $3.4 \mathrm{ppb}$. The pre-shift 2,3-pentanedione air concentration was $0.5 \mathrm{ppb}$, and post-shift air concentration was $2.2 \mathrm{ppb}$. 2,3-Hexanedione concentrations were below the LOD (less than $0.6 \mathrm{ppb}$ ) for both pre- and post-shift measurements.

\section{Bulk Samples and Headspace Analyses}

Table A6 presents the three bulk sample results using headspace analysis from our visit to the roasting and packaging facility. The highest concentrations of diacetyl ( $935 \mathrm{ppb}$ and $1,035 \mathrm{ppb})$ and 2,3-pentanedione (1,370 ppb and 1,670 ppb) were associated with whole, freshly-roasted beans taken directly from the cooling bin as they cooled. Green coffee beans did not have any detectable concentrations of diacetyl or 2,3-pentanedione. 2,3-Hexanedione concentrations were below the LOD (less than $207 \mathrm{ppb}$ ) in all of the samples.

\section{Real-time Monitoring: Total Volatile Organic Compounds (TVOCs), Carbon Dioxide, and Carbon Monoxide}

Table A7 presents the results from real-time monitoring of TVOCs, $\mathrm{CO}_{2}$, and $\mathrm{CO}$ during our visit to the roasting and packaging facility in March 2016. The average TVOC concentration around the roaster $(290 \mathrm{ppb})$ was lower than the average concentration in packaging near the auto-fill machine (401 ppb). However, the roaster showed higher peak concentrations (3,046 ppb maximum) compared to packaging (1,141 ppb maximum). $\mathrm{CO}_{2}$ levels at both the roaster and auto-fill machine were nearly the same. The roaster showed an average $\mathrm{CO}_{2}$ concentration of $515 \mathrm{ppm}$ while the auto-fill machine showed $496 \mathrm{ppm}$. Maximum $\mathrm{CO}_{2}$ levels were $627 \mathrm{ppm}$ at the roaster and $691 \mathrm{ppm}$ in the packaging area. Average CO levels were $0.2 \mathrm{ppm}$ and $0.3 \mathrm{ppm}$ at the roaster and auto-fill machine, respectively. The maximum $\mathrm{CO}$ level measured was $4.0 \mathrm{ppm}$ by the auto-fill machine in packaging.

\section{Ventilation Assessment at Coffee Roasting and Packaging Facility}

Mechanical ventilation to the roasting and packaging space was provided by a Trane (Piscataway, NJ) Voyager 12.5 ton packaged rooftop air-handling unit (AHU). The AHU fed a single main circular supply duct, equipped with three 1 foot $\times 3$ feet supply vents, which ran east-to-west toward the south end of the roasting and packaging space. Return air to the AHU passed through a single 15 -inch $\times 57$-inch return grille mounted on the ceiling just under the rooftop unit. Combined, the AHU was supplying about 3,700 cubic feet per minute (cfm) of supply air to the roasting and packaging area.

In addition to the rooftop AHU, there was a local exhaust hood installed above the two sample roasters along the eastern wall of the roasting and packaging space. The hood was connected to a switch-operated exhaust fan. The fan was only powered on during times the sample roasters were being used. However, when on, the fan removed $900 \mathrm{cfm}$ of air from the space. 
The roasting and packaging area was also equipped with two ceiling-mounted fans that were on during our March 2016 visit. While not providing any supply or exhaust to/from the space, they were serving to mix the air in the space.

The green bean storage room was equipped with a ductless-split heating, ventilation, and air-conditioning (HVAC) unit mounted high above the door into the office side of the facility. The unit did recirculate and condition air within the room but provided no fresh, outdoor air to the space. The room was also equipped with a ceiling-mounted fan that was in operation during our visit.

The offices and QC café were ventilated with a single Trane XV95 furnace that provided a total of $845 \mathrm{cfm}$ of supply air; $430 \mathrm{cfm}$ to the reception office area, $100 \mathrm{cfm}$ to the administrative office, $215 \mathrm{cfm}$ to the hallway just inside the main entrance, and $100 \mathrm{cfm}$ to the QC café. Three ducted return grilles, one each in the reception office, administrative office, and QC café, facilitated return air to the furnace. This unit did not provide any fresh, outdoor air to the occupied spaces.

As expected, differential pressure relationships between adjacent spaces were dependent on the ventilation scenario. When the roasting and packaging AHU and the office AHU were both off, or when only the office AHU was on, the roasting and packaging space was under negative pressure to the rest of the facility, the QC café was negative to the reception and administrative offices, and the reception and administrative offices were neutral to one another. Air flows from areas of higher, positive pressure to areas of lower, negative pressure. So, when the roasting and packaging AHU and the office AHU were both off, or when only the office AHU was on, the pressure relationships were as desired because air flowed from areas with lower alpha-diketone levels to areas with higher concentrations. However, when the roasting and packaging and office AHUs were both on or when only the roasting and packaging $\mathrm{AHU}$ was on, the roasting and packaging space remained negative to the green bean storage area, but the QC and reception office became slightly negative to roasting and packaging. In this scenario, potentially elevated levels of alpha-diketones could migrate to the QC café and reception office.

\section{Medical Survey at Coffee Roasting and Packaging Facility}

\section{Demographics}

Ten of 13 employees (77\%) participated in the medical survey, including four of six production employees. Half of the participants were male. All the participants were Caucasian with a mean age of 39 years and average tenure at the company of four years. Four participants reported working as roaster operators at other companies before coming to this facility. Six $(60 \%)$ of the 10 participants were current or former smokers.

All 10 participants reported working in or entering the production area, ranging from 30 minutes to 32 hours a week. Nine of 10 reported being within an arm's length of roasted coffee in one or more areas of the production process. 


\section{Symptoms and Self-Reported Diagnoses}

The prevalences of symptoms over the last year and last four weeks at the time of the survey are listed in Table A8. Nose symptoms were the most commonly reported symptom ( $\mathrm{n}=8$, $80 \%$ ), followed by eye symptoms ( $\mathrm{n}=7,70 \%)$. No employees reported improvement in their symptoms away from work; yet, three employees noted that their nose symptoms were caused or aggravated by dust, green coffee bean dust, or chaff.

Breathing trouble $(\mathrm{n}=6,60 \%)$ and awakening with chest tightness $(\mathrm{n}=6,60 \%)$ were the most commonly reported lower respiratory symptoms followed by asthma attack (40\%). Four of the six participants that reported lower respiratory symptoms also reported nasal, sinus problems, and/or physician-diagnosed hay fever or nasal allergies. No participants reported improvement of lower respiratory symptoms away from the workplace. One participant reported green coffee dust caused or aggravated his/her lower respiratory symptoms. Flu-like achiness or achy joints was the most commonly reported systemic symptom $(\mathrm{n}=7,70 \%)$.

Three participants reported a diagnosis of hay fever or nasal allergies, and four reported asthma. Except for one participant with asthma, these conditions were diagnosed prior to employment at the coffee roasting and packaging facility. No participants reported a diagnosis of chronic bronchitis, bronchiolitis obliterans, chronic obstructive pulmonary disease, interstitial lung disease, hypersensitivity pneumonitis, chemical pneumonitis, sarcoidosis, heart disease, or vocal cord dysfunction.

\section{Medical Tests}

All ten spirometry and impulse oscillometry tests were normal. Two of ten exhaled nitric oxide tests were interpreted as elevated; both participants reported a history of asthma.

\section{NHANES Comparison of Symptoms, Diagnoses, and Spirometry}

The SMRs for current and ever asthma were both elevated at 5.1 and 2.7, respectively (Table A9). SMRs for eye symptoms, nose symptoms, sinus problems, phlegm, and wheeze were not elevated.

\section{Café}

\section{Industrial Hygiene Survey at Coffee Café}

\section{Personal and Area Full-shift Air Sampling}

OSHA Methods 1013/1016

Table B1 presents the personal and area full-shift air sampling results from our March 2016 visit to the café. We collected five personal and four area full-shift air samples over the course of a single day. Full-shift personal samples collected on four employees in the café had higher exposures to diacetyl (2.2 ppb - 6.0 ppb) and 2,3-pentanedione (3.8 - 6.4 ppb) than the single personal sample collected on a kitchen employee ( $2.0 \mathrm{ppb}$ diacetyl and 2.2 ppb 2,3-pentanedione). While the sample on the kitchen employee was below the NIOSH RELs for diacetyl and 2,3-pentanedione, three of the four café employee personal samples were above the NIOSH REL for diacetyl of $5.0 \mathrm{ppb}$. None of the café employee personal 
samples exceeded the NIOSH REL for 2,3-pentanedione. All five personal samples collected were below the LOD for 2,3-hexanedione.

Four area samples were collected in the café space (none in the kitchen area). Diacetyl concentrations in these samples ranged from $3.7 \mathrm{ppb}$ to $7.3 \mathrm{ppb}$ and 2,3-pentanedione concentrations ranged from $3.7 \mathrm{ppb}$ to $7.2 \mathrm{ppb}$. All four full-shift area samples were below the LOD for 2,3-hexanedione.

\section{Personal Task-based Air Sampling \\ OSHA Methods 1013/1016}

Table B2 presents the OSHA Methods 1013/1016 personal task-based air concentrations from our visit to the café in March 2016, by individual task. Importantly, tasks associated with coffee roasting, grinding, and packaging are varied and as such the duration also varies. We collected three personal task-based air samples and the sample duration ranged from 12 to 16 minutes. One of these tasks lasted for 15 minutes, allowing for a direct comparison with the NIOSH STELs for diacetyl (25 ppb) and 2,3-pentanedione (31 ppb). An employee that made espresso drinks, including grinding the coffee beans, had the highest diacetyl (7.3 ppb) and 2,3-pentanedione (9.4 ppb) exposure; both of which were below the STELs. While not directly comparable to the STEL because their duration was not exactly 15 minutes, the two other task-based samples were also well below the STELs. All samples were below the LOD for 2,3-hexanedione.

\section{Instantaneous Evacuated Canisters}

Table B3 presents the personal task-based air concentrations determined using evacuated canisters from our café visit in March 2016. All evacuated canisters were equipped with an instantaneous flow controller with a sample duration of approximately 30 seconds. Results should not be compared with 15-minute STELs. We collected five personal taskbased canister air samples. Three of the five samples were collected in the breathing zone of employees making espresso drinks. Concentrations ranged from $6.5 \mathrm{ppb}-14.3 \mathrm{ppb}$ for diacetyl, 6.6 ppb - 14.2 ppb for 2,3-pentanedione, and from below the LOD to $6.5 \mathrm{ppb}$ for 2,3-hexanedione. The sample collected while an employee melted chocolate for hot cocoa had the highest diacetyl (16.8 ppb) and 2,3-pentanedione (16.1 ppb) concentrations, while the concentration of 2,3-hexanedione was $2.2 \mathrm{ppb}$. The last sample was collected while an employee steamed milk. That instantaneous exposure was $9.0 \mathrm{ppb}$ of diacetyl, $9.1 \mathrm{ppb}$ of 2,3-pentanedione, and $2.7 \mathrm{ppb}$ of 2,3-hexanedione.

\section{Source-based Air Sampling \\ Instantaneous Evacuated Canisters}

Table B4 presents source air sampling results from our March 2016 visit to the café. We collected eight source air samples using instantaneous evacuated canisters. The highest concentrations were measured in a sample taken at the grinder while an employee ground coffee for a bulk coffee brew. This sample gave concentrations of $215 \mathrm{ppb}$ of diacetyl, 229 ppb of 2,3-pentanedione, and $8.1 \mathrm{ppb}$ of 2,3-hexanedione. Other grinding sources also showed higher alpha-diketone concentrations. Two samples taken at the grinder used for pour overs gave $33.8 \mathrm{ppb}$ and $94.0 \mathrm{ppb}$ for diacetyl, $35.3 \mathrm{ppb}$ and $101 \mathrm{ppb}$ for 2,3-pentanedione, 
and $6.5 \mathrm{ppb}$ and $6.1 \mathrm{ppb}$ 2,3-hexanedione. A pour over occurs when a café employee measures out a portion of roasted coffee beans, grinds them, and then slowly pours hot water over the ground coffee by hand. A sample at the espresso grinder contained 54.2 ppb of diacetyl, $50.9 \mathrm{ppb}$ of 2,3-pentanedione, and $5.5 \mathrm{ppb}$ of 2,3-hexanedione. The other instantaneous source samples all contained lower concentrations of the alpha-diketones, with the next highest sample being the melting of chocolate with hot water, which showed 12.2 ppb of diacetyl, 12.1 ppb of 2,3-pentanedione, and 8.1 ppb of 2,3-hexanedione.

\section{Background Pre- and Post-shift Instantaneous Evacuated Canister Sampling}

Table B5 presents the instantaneous evacuated canister pre- and post-shift background air sampling results from our café visit. All of the samples collected were taken while standing in between the café service bar and the customer seating area. Both diacetyl and 2,3-pentanedione air concentrations increased over the course of the work day. The pre-shift diacetyl concentration was $3.0 \mathrm{ppb}$, and post-shift air concentration was $6.0 \mathrm{ppb}$. The preshift 2,3-pentanedione air concentration was $2.1 \mathrm{ppb}$, and post-shift air concentration was 5.4 ppb. 2,3-Hexanedione concentrations were below the LOD (less than $0.6 \mathrm{ppb}$ ) for both preand post-shift measurements.

\section{Bulk Samples and Headspace Analyses}

No bulk samples were taken for headspace analysis during our visit to the café in March 2016.

\section{Real-time Monitoring: Carbon Dioxide, Carbon Monoxide, and Total Volatile Organic Compounds}

Table B6 presents the results from real-time monitoring of TVOCs, $\mathrm{CO}_{2}$, and $\mathrm{CO}$ near the coffee grinders during our visit to the café in March 2016. The average TVOC concentration was $917 \mathrm{ppb}$. When measured beside the espresso grinders, $\mathrm{CO}_{2}$ levels increased steadily throughout the day. The concentration of $\mathrm{CO}_{2}$ in the air was around 1,700 ppm just before noon (when the measurement started) and continued to trend upwards to around 1,900 ppm around 2:45 pm (see Appendix C, Figure 1). The average CO level was 1.6 ppm, and 109.6 ppm was the maximum level measured.

\section{Ventilation Assessment at Coffee Café}

Heating, cooling, and air delivery for the café and associated kitchen was provided by a single Comfortmaker (United Technologies, Farmington, CT) residential-style AHU installed above the drop ceiling in the kitchen area. The model number of the unit could not be safely obtained. This unit was moving approximately $1,500 \mathrm{cfm}$ of air. However, the air being moved was $100 \%$ recirculated from the café spaces back into the café without bringing in any fresh, outdoor air. During the NIOSH visit, some café employees reported a "stuffy" feeling when at the café. Bringing in more outdoor air may eliminate the "stuffy" feeling reported by some employees. There were no local exhaust ventilation systems in place in the café, including in the attached kitchen space.

No differential pressure measurements were taken at the café. The café space was one large open area, and the door to the kitchen was always open. There were no critical adjacent 
spaces where differential pressure relationships would be useful.

\section{Medical Survey at Café}

Five of 13 café employees (38\%) participated in the medical survey. Nose symptoms followed by sinusitis or sinus problems were the most commonly reported symptoms. One person reported lower respiratory symptoms. All the participants reported that nothing at work caused or aggravated their symptoms, and they did not have any improvement in their symptoms away from the café. All five spirometry and exhaled nitric oxide tests were normal. Four of five impulse oscillometry tests were normal while one was interpreted as a possible small airways abnormality. Because of the small number of participants and the need to protect individuals' privacy, we cannot provide more detailed results that would shed light on possible work-relatedness.

\section{Discussion}

Diacetyl, 2,3-pentanedione, 2,3-hexanedione, other VOCs, and other chemicals such as CO and $\mathrm{CO}_{2}$ are naturally produced when coffee beans are roasted, and grinding the roasted coffee beans produces greater surface area for the off-gassing of these chemicals [Anderson et al. 2003; Akiyama et al. 2003; Daglia et al. 2007; Newton 2002; Nishimura et al. 2003; Raffel and Thompson 2013]. Occupational exposure to diacetyl and 2,3-pentanedione can cause loss of lung function and the lung disease obliterative bronchiolitis [NIOSH 2016].

\section{Coffee Roasting and Packaging Facility}

\section{Alpha-Diketones}

\section{Personal Air Sampling}

None of the 11 personal full-shift air samples taken at the roasting and packaging facility using standard OSHA methods were above the NIOSH RELs for diacetyl or 2,3-pentanedione, and none were above the LOD for 2,3-hexanedione. The highest full-shift personal exposure to diacetyl was $4.7 \mathrm{ppb}$ collected from a roasting and packaging employee. While our sampling results indicate that workers in the roasting and packaging area were exposed to levels below the NIOSH RELs for diacetyl and 2,3-pentanedione, some results were approaching the REL for diacetyl. Increases in production volume, modifications to work practices, and/or changes in ventilation could result in worker exposures above the REL.

As noted earlier, the RELs should be used as a guideline to indicate when steps should be taken to reduce exposures in the workplace. The risks associated with the levels we measured in March 2016 were acceptable under NIOSH recommendations. As described in the quantitative risk assessment from the NIOSH Criteria Document (Tables 5-27 and 5-34) [NIOSH 2016], after a 45-year working lifetime exposure to 5 ppb (a concentration slightly higher than the highest concentration measured at this facility), NIOSH estimated about 1 in 1,000 workers would develop reduced lung function $\left(\mathrm{FEV}_{1}\right.$ below the lower limit of normal). NIOSH predicted that around 1 in 10,000 workers exposed to diacetyl at 5 ppb would 
develop more severe lung function reduction $\left(\mathrm{FEV}_{1}\right.$ below $60 \%$ predicted, defined as at least moderately severe by the American Thoracic Society [Pellegrino et al. 2005]). The effects of a working lifetime exposure at $4.7 \mathrm{ppb}$ would be somewhat less than those for $5 \mathrm{ppb}$. NIOSH recommends keeping diacetyl concentrations below $5 \mathrm{ppb}$ because at this level, the risk of reduced lung function after a working lifetime of exposure is below 1 in 1,000 workers. NIOSH recommends taking steps to reduce diacetyl exposures to below the REL of $5 \mathrm{ppb}$ whenever possible.

\section{Area Air Sampling}

All 17 full-shift area samples collected were below the NIOSH RELs for diacetyl and 2,3-pentanedione. Area samples are not directly comparable to RELs, because the samples are not collected directly on workers. However, using the RELs as points of reference can help determine areas of the facility with the potential for hazardous personal exposures. No specific areas of concern were identified from our March 2016 area sampling results.

\section{Task-based Exposures}

Coffee processing involves multiple tasks that may cause intermittent exposure to diacetyl and 2,3-pentanedione. Traditional full-shift sampling will not characterize these intermittent, peak exposures. Evaluating intermittent and task-based exposures to diacetyl and 2,3-pentanedione is difficult with current validated sampling methods (OSHA Methods 1013/1016). Since coffee processing tasks are intermittent and short in duration, with some only lasting a few seconds or minutes, we used instantaneous evacuated canisters to sample these shorter tasks and OSHA Methods 1013/1016 for longer duration tasks. We did not collect 15-minute samples at this facility with the intention to compare to the NIOSH STELs; instead, we sampled by task, with varying durations, to understand which tasks may have contributed to higher exposures to diacetyl and 2,3-pentanedione.

Our task-based air sampling revealed that some tasks had higher air concentrations of diacetyl and/or 2,3-pentanedione than other tasks. Using OSHA Method 1013/1016 (Table A2), grinding tasks in the production area resulted in the highest alpha-diketone exposures (9.4 ppb diacetyl; 9.9 ppb 2,3-pentanedione). Samples taken with instantaneous evacuated canisters (Table A3) also showed high alpha-diketone concentrations associated with grinding activities (maximum: $458 \mathrm{ppb}$ diacetyl; $431 \mathrm{ppb}$ 2,3-pentanedione). Since grinding roasted coffee beans is a source of alpha-diketone emissions, the frequency and duration of grinding tasks affects the resultant full-shift air concentrations for alpha-diketones. While all full-shift samples were below the RELs during our visit, increases in production volume, modifications to work practices, and/or changes in ventilation could result in worker exposures above the REL. If this were to occur, reducing exposures caused by grinding coffee would be a good first step to reducing overall exposures to roasting and packaging workers. Potentially effective means of mitigating exposure to volatile coffee emissions are to eliminate or reduce grinding of whole beans within the general production area, to install local exhaust ventilation on the grinding equipment, and/or to automate the grinding process to separate the employees from the source of exposure. 


\section{Bulk Samples}

Diacetyl is not found in green beans and forms later during the coffee roasting process [Daglia et al. 2007]. As expected, we found that roasted coffee emits alpha-diketones (e.g., diacetyl, 2,3-pentanedione) into the headspace of sealed vessels, indicating that roasted coffee is a considerable source of alpha-diketones in the facility. Bulk headspace analysis of roasted coffee beans indicated the presence of diacetyl and 2,3-pentanedione (Table A6), while alpha-diketone concentrations in the headspace above green coffee beans were all below the LODs.

\section{Real-time Sampling}

$\mathrm{CO}$ and $\mathrm{CO}_{2}$ concentrations in the air did not exceed applicable exposure limits. Since roasted coffee is known to emit $\mathrm{CO}, \mathrm{CO}_{2}$, and total VOCs, employees should not place their head or face inside storage bins or directly outside uncovered bins containing roasted coffee as a standard work practice.

\section{Ventilation}

The rooftop AHU, office furnace, innovative and effective dust-collection system, and associated ductwork at the production facility were all well-maintained and in good working order.

The AHU and furnace were both equipped with proper configurations of air filters. While the office furnace system did not provide any fresh, outdoor air to the space it served, the rooftop AHU serving the roasting and packaging area was equipped with an economizer system. Some fresh, outdoor air was supplied to the production space at all times; the amount could increase up to $100 \%$ when outdoor conditions were favorable. The outdoor conditions during our March 2016 visit were not favorable for economizer operation, so it is likely that only minimal outdoor air was being supplied to the space at that time; we did not have equipment that allowed us to accurately measure the fraction of outdoor air being supplied. During times when more outdoor air is supplied to the space, additional dilution of airborne contaminants would occur. At the same time, the unit was controlled by a thermostat. The unit shut off when the temperature set-point on the thermostat was achieved. During these times, no dilution ventilation is supplied to the space. Consideration should be given to running the rooftop AHU at all times during production activities.

At times when the roasting and packaging and office AHUs were both on or when only the roasting and packaging AHU was on, the roasting and packaging space remained negative to the green bean storage area, but the QC café and reception office became slightly negative to roasting and packaging. These scenarios could result in airborne contaminants from the roasting and packaging space being pulled into the QC café and reception office. Since overall airborne concentrations of alpha-diketones were low throughout the facility, air movement into the non-production spaces was not an issue during our March 2016 visit. If production volume increases in the future, air movement should be revisited. Consideration should be given to installing better seals, including door floor sweeps on the two doors between the production space and the QC café and reception areas. This would reduce the likelihood of any airborne contaminants generated in production from traveling into those 
spaces, regardless of the ventilation system operating scenario.

\section{Medical Survey at Coffee Roasting and Packaging Facility}

Overall, mucous membrane symptoms, specifically eye and nose symptoms were the most commonly reported symptoms. Some production employees reported their symptoms were caused or aggravated by green coffee dust and chaff. Coffee dust is an organic dust and, as noted earlier, exposure to coffee dust is known to cause respiratory symptoms and is a known risk factor for occupational asthma [Karr et al. 1978; Zuskin et al. 1979, 1985, 1993; Thomas et al. 1991; Sakwari et al. 2013].

Upper respiratory disease such as allergic rhinitis (hay fever, nasal allergies) and sinusitis are sometimes associated with lower respiratory symptoms and asthma and may precede the diagnosis of asthma [Shaaban et al. 2008; EAACI Task Force on Occupational Rhinitis 2008; Rondón et al. 2012, 2017; Sahay et al. 2016]. Five times as many participants as expected reported current asthma than in the general population with a similar demographic distribution although three of the four participants with asthma were diagnosed prior to employment at the coffee roasting and packaging facility. Upper respiratory involvement (e.g., rhinitis, sinusitis) can result in suboptimal control of asthma. Four of the six participants that reported lower respiratory symptoms also reported nasal or sinus problems or physician-diagnosed hay fever or nasal allergies. Green coffee dust is thought to be a more potent allergen than roasted coffee dust because roasting destroys some of the allergenic activity [Lehrer et al. 1978]. As discussed in the recommendations section, one way to prevent symptoms related to green coffee dust and chaff, might be to make N95 disposable filtering facepiece respirators available for voluntary use when working with green beans and chaff.

All participants with respiratory symptoms reported that their symptoms did not improve away from work. These respiratory symptoms and the two elevated exhaled nitric oxide tests could be related to workplace exposures or to other factors. Indeed, some employees had respiratory diagnoses that preceded employment at this facility. However, our findings of respiratory symptoms caused or aggravated by dust, green bean dust, or chaff in $40 \%$ of medical survey participants suggest a burden of respiratory problems in this workforce. Because of the small number of participants and the need to protect individuals' privacy, we cannot provide more detailed results that might shed light on possible work-relatedness, such as health measures by job title or task. We mailed each participant their individual lung function test results with an explanation of the results and recommended each participant provide the information to their personal physician.

\section{Café}

\section{Alpha-Diketones}

Personal Air Sampling

Five personal full-shift air samples were collected on café employees; four on employees that worked at the main café service bar and one on the kitchen employee. Three of the 
four service bar employees had higher exposures to diacetyl (2.2 ppb to $6.0 \mathrm{ppb})$ and 2,3-pentanedione $(3.8-6.4 \mathrm{ppb})$ than the kitchen employee $(2.0 \mathrm{ppb}$ diacetyl and $2.2 \mathrm{ppb}$ 2,3-pentanedione). While the sample on the kitchen employee was below the NIOSH RELs for diacetyl and 2,3-pentanedione, three of the four café worker personal samples were over the NIOSH REL for diacetyl of $5.0 \mathrm{ppb}$. None of the café employee personal samples exceeded the NIOSH REL for 2,3-pentanedione. All five personal samples collected were below the LOD for 2,3-hexanedione.

As previously discussed, the RELs should be used as a guideline to indicate when steps should be taken to reduce exposures in the workplace. The risks associated with the levels we measured in March 2016 were higher than NIOSH recommends. As described in the quantitative risk assessment from the NIOSH Criteria Document (Table 5-27) [NIOSH 2016], after a 45-year working lifetime exposure to $10 \mathrm{ppb}$ (a concentration somewhat higher than the highest concentration measured at this café), NIOSH estimated less than 2 in 1,000 workers would develop reduced lung function ( $\mathrm{FEV}_{1}$ below the 5 th percentile). NIOSH predicted that around 2 in 10,000 workers exposed to diacetyl at $10 \mathrm{ppb}$ would develop more severe lung function reduction ( $\mathrm{FEV}_{1}$ below $60 \%$ predicted, defined as moderately severe by the American Thoracic Society [Pellegrino et al. 2005]). NIOSH recommends keeping diacetyl concentrations below 5 ppb because at this level, the risk of reduced lung function after a working lifetime of exposure is below 1 in 1,000 workers. NIOSH recommends taking steps to reduce diacetyl exposures to below the REL of $5 \mathrm{ppb}$ whenever possible.

\section{Area Air Sampling}

Four area samples were collected in the café space; none were collected in the kitchen area. These samples ranged in diacetyl concentrations from $3.7 \mathrm{ppb}$ to $7.3 \mathrm{ppb}$ and in 2,3-pentanedione concentrations from $3.7 \mathrm{ppb}$ to $7.2 \mathrm{ppb}$. The highest diacetyl (7.3 ppb) and 2,3-pentanedione (7.2 ppb) concentrations were in the sample collected at the espresso grinders. The other two samples behind the café bar were both over the NIOSH REL for diacetyl; the sample beside the espresso machine gave $6.0 \mathrm{ppb}$, and the sample between the brewed coffee carafes gave $5.1 \mathrm{ppb}$. The sample collected in the café seating area near the trash cans showed $3.7 \mathrm{ppb}$ diacetyl. All four full-shift area samples collected were below the REL for 2,3-pentanedione and below the LOD for 2,3-hexanedione. Area samples cannot be directly compared to RELs, because the samples are not collected directly on workers. However, using the RELs as points of reference can help determine areas of the facility with the potential for hazardous personal exposures. In general, the entire area behind the café service bar showed area concentrations that could lead to personal exposures above the diacetyl REL based on our March 2016 area sampling results. These diacetyl concentrations might be mitigated by bringing in more outdoor air as discussed in the ventilation section below.

\section{Task-based Exposures}

We collected three personal task-based air samples on silica gel tubes. One 15-minute sample was collected on an employee that made espresso drinks, including grinding the coffee beans, had the highest diacetyl (7.3 ppb) and 2,3-pentanedione (9.4 ppb) exposures. This personal task-based sample result was below the NIOSH STELs for diacetyl (25 ppb) and 
2,3-pentanedione (31 ppb). All samples were below the LOD for 2,3-hexanedione.

We also collected five personal task-based samples using instantaneous evacuated canisters. Three of the five samples were collected in the breathing zone of employees making espresso drinks. Those samples showed maximum concentrations of $14.3 \mathrm{ppb}$ for diacetyl, $14.2 \mathrm{ppb}$ for 2,3-pentanedione, and $6.5 \mathrm{ppb}$ for 2,3-hexanedione. Interestingly, a sample collected while an employee melted chocolate with hot water gave the highest diacetyl (16.8 ppb) and 2,3-pentanedione (16.1 ppb) concentrations, while the concentration of 2,3-hexanedione was $2.2 \mathrm{ppb}$. While it is known that chocolate can release alpha-diketones [Aculey et al. 2010; Abeygunasekera and Jansz 1989], we do not know whether the measured concentrations were from the chocolate, nearby coffee-related activities, or the combination of the two. A sample collected while an employee steamed milk gave $9.0 \mathrm{ppb}$ of diacetyl, $9.1 \mathrm{ppb}$ of 2,3-pentanedione, and $2.7 \mathrm{ppb}$ of 2,3-hexanedione. Again, alpha-diketones have been associated with dairy products [Shibamoto 2014], but we do not know whether the measured concentrations were the result of the milk or other nearby activities.

\section{Bulk Samples}

No bulk samples for headspace analysis were collected at the café.

\section{Real-time Sampling}

The average TVOC concentration was $917 \mathrm{ppb}$, but that average masks some large, shortduration concentration spikes while the grinders were actually operating. The largest concentration spike measured 25,444 ppb during grinding. When measured beside the espresso grinders, $\mathrm{CO}_{2}$ levels increased steadily throughout the day, and were higher than recommended (see discussion on ventilation below). The concentration of $\mathrm{CO}_{2}$ in the air started around 1,700 ppm and climbed to around 1,900 ppm after nearly 3 hours (Appendix $\mathrm{C}$, Figure 1). Concentrations of $\mathrm{CO}_{2}$ at these levels are indicative of a lack of outdoor air supplied to the space, and they can result in the space feeling "stale" or "stuffy."

The average $\mathrm{CO}$ level throughout the day was 1.6. However, like with the TVOCs, the CO level showed large, short-duration spikes associated with grinding activities. The highest CO level measured was $109.6 \mathrm{ppm}$, which occurred at the same time as the peak TVOC measurement. In both cases, the peak concentrations were only measured for a few seconds before quickly falling back to more typical background concentrations.

\section{Ventilation}

The AHU that provided ventilation to the café was recirculating $100 \%$ of the air from the café spaces without bringing in any outdoor air. This ventilation configuration could easily result in the elevated $\mathrm{CO}_{2}$ levels witnessed during the NIOSH visit. An adequate supply of outdoor air, typically delivered through the HVAC system, is necessary in any indoor environment to dilute pollutants that are released by equipment, building materials, furnishings, products, and people. $\mathrm{CO}_{2}$ is a normal constituent of exhaled breath; thus, $\mathrm{CO}_{2}$ will also increase during building occupancy. $\mathrm{CO}_{2}$ levels are routinely collected in air quality studies because they can indicate whether a sufficient quantity of outdoor air is being introduced to an occupied space for acceptable odor control. The American National Standards Institute (ANSI) and ASHRAE 
have developed consensus standards and guidelines for HVAC systems. ASHRAE notes in an informative appendix to ANSI/ASHRAE Standard 62.1-2016: Ventilation for Acceptable Indoor Air Quality that indoor $\mathrm{CO}_{2}$ concentrations no greater than $700 \mathrm{ppm}$ above outdoor $\mathrm{CO}_{2}$ concentrations will satisfy a substantial majority (about $80 \%$ ) of occupants [ANSI/ ASHRAE 2016]. This would typically correspond to indoor concentrations below 1,200 ppm since outdoor $\mathrm{CO}_{2}$ concentrations usually range between 375 to $500 \mathrm{ppm}$. However, $\mathrm{CO}_{2}$ is not an effective indicator of ventilation adequacy if the ventilated area is not occupied at its usual occupant density at the time the $\mathrm{CO}_{2}$ is measured. Elevated $\mathrm{CO}_{2}$ concentrations suggest that other indoor contaminants may also be increased. If $\mathrm{CO}_{2}$ concentrations are elevated, the amount of outdoor air introduced into the ventilated space may need to be increased.

In some cases, building owners/managers or occupants will open doors or windows to increase the amount of outdoor air coming into their building. However, relying on open doors may cause problems. For example, the air coming into the building through the doors may not reach all of the occupied space. The incoming air is unfiltered and may contain outdoor air pollutants such as pollen and dust. Additionally, open doors may affect the ability of the HVAC system to adequately control temperature and humidity. ASHRAE guidelines provide specific details on ventilation for acceptable indoor environmental quality. A ventilation system expert can help meet ASHRAE ventilation guidelines in the building. ANSI/ASHRAE 62.1-2016 recommends outdoor air supply rates that take into account people-related sources as well as building-related sources. While there are no specific recommendations in the standard for coffee cafés, there are several similar spaces that can be used as effective guidance. For restaurant dining rooms, café/fast-food dining, and bars and cocktail lounges, $7.5 \mathrm{cfm} /$ person is recommended for people-related sources, and an additional $0.18 \mathrm{cfm}$ for every square foot $\left(\mathrm{cfm} / \mathrm{ft}^{2}\right)$ of occupied space is recommended to account for building-related sources. To find rates for other indoor spaces, refer to Table 6.2.2.1, which is found in ANSI/ASHRAE 62.1-2016 [ANSI/ASHRAE 2016].

A qualified ventilation contractor can help with ways to modify the existing ventilation system to bring in appropriate levels of outdoor air to reduce indoor $\mathrm{CO}_{2}$ concentrations and eliminate the "stuffy" feeling reported during the NIOSH visit. Using ASHRAE Standard 62.1-2016 as a guide, given the floor space of the café, roughly $750 \mathrm{cfm}$ of outdoor air should be introduced to the space at maximum occupancy. In addition to reducing indoor $\mathrm{CO}_{2}$ levels, introducing fresh, outdoor air into the space will also dilute airborne concentrations of diacetyl and 2,3-pentanedione.

\section{Medical Survey}

Participants reported that none of their symptoms were caused or aggravated by something at work, and their symptoms did not improve away from work. All spirometry and exhaled nitric oxide tests were normal. Four of five impulse oscillometry tests were normal while one was interpreted as a possible small airways abnormality. Because of the small number of participants and the need to protect individuals' privacy, we cannot provide more detailed results, such as health measures by job title or task. We mailed each participant their individual lung function test results with an explanation of the results and recommended each participant provide the information to their personal physician. 


\section{Conclusions}

\section{Coffee Roasting and Packaging Facility}

All full-shift personal samples were below the RELs for diacetyl and 2,3-pentanedione. Grinding tasks in the production area resulted in the highest alpha-diketone exposures. $\mathrm{CO}_{2}$ and $\mathrm{CO}$ concentrations in the air did not exceed applicable exposure limits. Eye and nose symptoms were the most commonly reported symptoms. Breathing trouble and awakening with chest tightness were the most commonly reported lower respiratory symptom. All participants with upper or lower respiratory symptoms reported that their symptoms did not improve away from work. These respiratory symptoms and the lung function abnormalities could be related to workplace exposures or to other factors. However, our findings of respiratory symptoms caused or aggravated by dust, green bean dust, or chaff in $40 \%$ of medical survey participants suggest a burden of respiratory problems in this workforce.

\section{Café}

Three of the five full-shift personal air samples were above the NIOSH REL for diacetyl of $5.0 \mathrm{ppb}$, with the highest measured concentration of $6.0 \mathrm{ppb}$. Grinding tasks resulted in the highest alpha-diketone exposures. $\mathrm{CO}_{2}$ levels increased slightly throughout the day and were higher than recommended. The AHU that provided ventilation to the café was recirculating $100 \%$ of the air from the café spaces without bringing in any outdoor air. No local exhaust ventilation systems were in place in the café or kitchen areas. Nose symptoms followed by sinusitis or sinus problems were the most commonly reported symptoms; participants did not report any work-related symptoms. All spirometry and exhaled nitric oxide tests were normal. An adequate supply of outdoor air is necessary in any indoor environment to dilute pollutants. We recommend training employees about workplace hazards and working with a ventilation expert to bring in appropriate levels of outdoor air to meet ventilation guidelines in the building.

\section{Recommendations}

On the basis of our findings, we recommend the actions listed below. Our recommendations are based on an approach known as the hierarchy of controls. This approach groups actions by their likely effectiveness in reducing or removing hazards. In most cases, the preferred approach is to eliminate hazardous materials or processes and install engineering controls to reduce exposure or shield employees. Until such controls are in place, or if they are not effective or feasible, administrative measures and personal protective equipment might be needed.

\section{Coffee Roasting and Packaging Facility}

\section{Engineering Controls}

Engineering controls reduce employees' exposures by removing the hazard from the process or by placing a barrier between the hazard and the employee. Engineering controls protect employees effectively without placing primary responsibility of implementation on the employee. 
1. Run the rooftop AHU at all times during production activities.

2. Install better seals, including door floor sweeps on the two doors between the production space and the QC café and reception areas. This would reduce the likelihood of any airborne contaminants generated in production from traveling into those spaces, regardless of how the ventilation system is operated.

3. If increases to production volumes, modification to current work practices, and/ or changes in ventilation occur, conduct additional air sampling to verify that the modifications have not resulted in alpha-diketone exposures above the NIOSH RELs. If exposures above the RELs are noticed, additional engineering controls will be necessary.

\section{Administrative Controls}

The term administrative controls refers to employer-dictated work practices and policies to reduce or prevent hazardous exposures. Their effectiveness depends on employer commitment and employee acceptance. Regular monitoring and reinforcement are necessary to ensure that policies and procedures are followed consistently.

1. Ensure employees understand potential hazards (e.g., diacetyl, 2,3-pentanedione, CO, $\mathrm{CO}_{2}$, green and roasted coffee dust) in the workplace and how to protect themselves. OSHA's Hazard Communication Standard, also known as the "Right to Know Law" [29 CFR 1910.1200] requires that employees are informed and trained on potential work hazards and associated safe practices, procedures, and protective measures.

2. Minimize production tasks that require employees to place their heads inside roasted bean bins.

3. Employees should report new, persistent, or worsening symptoms to their personal healthcare provider and, as instructed by their employer, to a designated individual at their workplace.

\section{Personal Protective Equipment}

The effectiveness of personal protective equipment in the form of respiratory protection in controlling respiratory exposures depends on avoiding breakdowns in implementation can result in insufficient protection. Proper use of respiratory protection (respirators) requires a comprehensive respiratory protection program and a high level of employee and management involvement and commitment to assure that the right type of respirator is chosen for each hazard, respirators fit users and are maintained in good working order, and respirators are worn when they are needed. Supporting programs such as training, change-out schedules, and medical assessment may be necessary. Respirators should not be the sole method for controlling hazardous inhalation exposures. Rather, respirators should be used until effective engineering and administrative controls are in place.

1. Make N95 disposable filtering facepiece respirators available for voluntary use for protection against green or roasted coffee dust exposure such as when working with 
green coffee beans or chaff. N95 users should receive a copy of Appendix D of the OSHA Respiratory Protection Standard (https:/www.osha.gov/pls/oshaweb/owadisp.

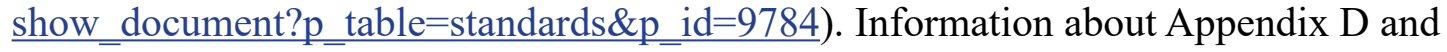
voluntary use of respirators can be found on the OSHA website at https://www.osha. gov/video/respiratory protection/voluntaryuse transcript.html.

Please be aware that N95s are not protective against alpha-diketones (diacetyl, 2,3-pentanedione, or 2,3-hexanedione). In cases of dual exposure to dust and alphadiketones, NIOSH-certified organic vapor cartridges (for the alpha-diketones) and particulate cartridges/filters (for the dust) would be warranted.

\section{Smoking Cessation Program}

In a workplace with risk of occupational lung disease, prevention of smoking-related lung disease is important and makes the detection of work-related adverse effects easier. We recommend implementing a smoking cessation program to assist employees to stop smoking. The Centers for Disease Control and Prevention offers tools and resources for setting up a smoking cessation program [CDC 2017].

\section{Café}

\section{Engineering Controls}

Engineering controls reduce employees' exposures by removing the hazard from the process or by placing a barrier between the hazard and the employee. Engineering controls protect employees effectively without placing primary responsibility of implementation on the employee.

1. Work with a ventilation expert to bring in appropriate levels of outdoor air to meet ASHRAE ventilation guidelines in the building. Using ASHRAE Standard 62.1-2016 as a guide, given the floor space of the café, roughly $750 \mathrm{cfm}$ of outdoor air should be introduced to the space at maximum occupancy.

2. Conduct follow-up air sampling to verify that the modifications have been effective in reducing $\mathrm{CO}_{2}$ levels below ASHRAE guidelines and alpha-diketone exposures to below the NIOSH RELs. If diacetyl and 2,3-pentanedione concentrations are not maintained below the RELs, additional engineering controls may be necessary.

\section{Administrative Controls}

The term administrative controls refers to employer-dictated work practices and policies to reduce or prevent hazardous exposures. Their effectiveness depends on employer commitment and employee acceptance. Regular monitoring and reinforcement are necessary to ensure that policies and procedures are followed consistently.

1. Ensure employees understand potential hazards (e.g., diacetyl, 2,3-pentanedione, $\mathrm{CO}, \mathrm{CO}_{2}$, coffee dust) in the workplace and how to protect themselves. OSHA's 
Hazard Communication Standard, also known as the "Right to Know Law" [29 CFR 1910.1200] requires that employees are informed and trained on potential work hazards and associated safe practices, procedures, and protective measures.

2. Employees should report new, persistent, or worsening symptoms to their personal healthcare provider and, as instructed by their employer, to a designated individual at their workplace. 


\section{Appendix A: Coffee Roasting and Packaging Facility Tables}

Table A1. OSHA Methods 1013/1016 full-shift personal and area air sampling results by location, NIOSH industrial hygiene survey at roasting and packaging facility, March 2016.

\begin{tabular}{|c|c|c|c|c|c|c|c|}
\hline Analyte & Sample Type & Location & $\mathbf{N}$ & $\begin{array}{c}\text { Above } \\
\text { LOD N } \\
(\%)\end{array}$ & $\begin{array}{c}\text { Minimum } \\
\text { Concentration } \\
(\mathbf{p p b})\end{array}$ & $\begin{array}{c}\text { Maximum } \\
\text { Concentration } \\
(\mathbf{p p b})\end{array}$ & $\begin{array}{c}\text { Above } \\
\text { REL } \\
\text { N }\end{array}$ \\
\hline Diacetyl & Personal & Office/Production & 1 & $1(100 \%)$ & 1.0 & 1.0 & 0 \\
\hline Diacetyl & Personal & Office Area & 4 & $4(100 \%)$ & 0.9 & 1.4 & 0 \\
\hline Diacetyl & Personal & Production Area & 5 & $5(100 \%)$ & 1.5 & 4.7 & 0 \\
\hline Diacetyl & Personal & QC and Roasting & 1 & $1(100 \%)$ & 2.1 & 2.1 & 0 \\
\hline Diacetyl & Area & Green Bean Storage & 2 & $2(100 \%)$ & 1.0 & 2.8 & N/A \\
\hline Diacetyl & Area & Office Area & 4 & $4(100 \%)$ & 0.9 & 1.3 & N/A \\
\hline Diacetyl & Area & Production Area & 9 & $9(100 \%)$ & 0.6 & 4.3 & N/A \\
\hline Diacetyl & Area & QC Area & 2 & $2(100 \%)$ & 1.3 & 1.8 & N/A \\
\hline 2,3-Pentanedione & Personal & Office/Production & 1 & $1(100 \%)$ & 1.0 & 1.0 & 0 \\
\hline 2,3-Pentanedione & Personal & Office Area & 4 & $4(100 \%)$ & 0.9 & 1.6 & 0 \\
\hline 2,3-Pentanedione & Personal & Production Area & 5 & $5(100 \%)$ & 1.1 & 3.9 & 0 \\
\hline 2,3-Pentanedione & Personal & QC and Roasting & 1 & $1(100 \%)$ & 1.8 & 1.8 & 0 \\
\hline 2,3-Pentanedione & Area & Green Bean Storage & 2 & $2(100 \%)$ & 0.7 & 2.1 & N/A \\
\hline 2,3-Pentanedione & Area & Office Area & 4 & $4(100 \%)$ & 0.8 & 1.3 & N/A \\
\hline 2,3-Pentanedione & Area & Production Area & 9 & $9(100 \%)$ & 0.5 & 3.6 & N/A \\
\hline 2,3-Pentanedione & Area & QC Area & 2 & $2(100 \%)$ & 1.5 & 1.9 & N/A \\
\hline 2,3-Hexanedione & Personal & Office/Production & 1 & $0(0 \%)$ & $<0.5$ & $<0.5$ & - \\
\hline 2,3-Hexanedione & Personal & Office Area & 4 & $0(0 \%)$ & $<0.5$ & $<0.5$ & - \\
\hline 2,3-Hexanedione & Personal & Production Area & 5 & $0(0 \%)$ & $<0.4$ & $<0.5$ & - \\
\hline 2,3-Hexanedione & Personal & QC and Roasting & 1 & $0(0 \%)$ & $<0.4$ & $<0.4$ & - \\
\hline 2,3-Hexanedione & Area & Green Bean Storage & 2 & $0(0 \%)$ & $<0.5$ & $<0.5$ & N/A \\
\hline 2,3-Hexanedione & Area & Office Area & 4 & $0(0 \%)$ & $<0.5$ & $<0.5$ & $\mathrm{~N} / \mathrm{A}$ \\
\hline 2,3-Hexanedione & Area & Production Area & 9 & $0(0 \%)$ & $<0.5$ & $<0.5$ & N/A \\
\hline 2,3-Hexanedione & Area & QC Area & 2 & $0(0 \%)$ & $<0.5$ & $<0.5$ & N/A \\
\hline
\end{tabular}

Note: $\mathbf{N I O S H}=$ National Institute for Occupational Safety and Health; $Q \mathrm{C}=$ quality control; $N=$ number of samples;

Above LOD N (\%) = number and percentage of samples above the limit of detection (LOD); < indicates below the LOD; Above REL N=number of samples above the NIOSH recommended exposure limit (REL); ppb=parts per billion; N/A indicates that NIOSH RELs are specified for personal air samples, and cannot be used for direct comparisons with area samples; "-_indicates that there is currently no REL for 2,3-hexanedione. 
Table A2. Summary of OSHA Methods 1013/1016 personal task-based air sampling results, NIOSH industrial hygiene survey at roasting and packaging facility, March 2016.

\begin{tabular}{|llccccc|}
\hline \multicolumn{1}{|c}{ Analyte } & \multicolumn{1}{c}{ Task } & $\mathbf{N}$ & $\begin{array}{c}\text { Above } \\
\text { LOD N } \\
\mathbf{( \% )}\end{array}$ & $\begin{array}{c}\text { Minimum } \\
\text { Concentration } \\
\text { (ppb) }\end{array}$ & $\begin{array}{c}\text { Maximum } \\
\text { Concentration } \\
\text { (ppb) }\end{array}$ & $\begin{array}{c}\text { Mean } \\
\text { (minutes) } \\
\text { Sample } \\
\text { Duration } \\
\text { (range) }\end{array}$ \\
\hline Diacetyl & Grinding coffee beans & 3 & $2(67 \%)$ & $<2.1$ & 9.4 & $10(7-17)$ \\
Diacetyl & Making labels & 1 & $0(0 \%)$ & $<0.9$ & $<0.9$ & 15 \\
Diacetyl & Packaging coffee & 4 & $3(75 \%)$ & $<0.9$ & 6.8 & $15(15-15)$ \\
Diacetyl & Quality Control & 4 & $2(50 \%)$ & $<1.6$ & 3.7 & $11(7-16)$ \\
Diacetyl & Roasting coffee beans & 13 & $4(31 \%)$ & $<0.8$ & 4.5 & $15(15-17)$ \\
\hline 2,3-Pentanedione & Grinding coffee beans & 3 & $3(100 \%)$ & 3.7 & 9.9 & $10(7-17)$ \\
2,3-Pentanedione & Making labels & 1 & $0(0 \%)$ & $<1.0$ & $<1.0$ & 15 \\
2,3-Pentanedione & Packaging coffee & 4 & $3(75 \%)$ & $<1.0$ & 4.3 & $15(15-15)$ \\
2,3-Pentanedione & Quality Control & 4 & $3(75 \%)$ & $<=1.8$ & 4.5 & $11(7-16)$ \\
2,3-Pentanedione & Roasting coffee beans & 13 & $6(46 \%)$ & $<0.8$ & 3.0 & $15(15-17)$ \\
\hline 2,3-Hexanedione & Grinding coffee beans & 3 & $0(0 \%)$ & $<1.3$ & $<3.1$ & $10(7-17)$ \\
2,3-Hexanedione & Making labels & 1 & $0(0 \%)$ & $<1.4$ & $<1.4$ & 15 \\
2,3-Hexanedione & Packaging coffee & 4 & $0(0 \%)$ & $<1.4$ & $<1.4$ & $15(15-15)$ \\
2,3-Hexanedione & Quality Control & 4 & $0(0 \%)$ & $<1.3$ & $<3.0$ & $11(7-16)$ \\
2,3-Hexanedione & Roasting coffee beans & 13 & $0(0 \%)$ & $<1.2$ & $<1.5$ & $15(15-17)$ \\
\hline
\end{tabular}

Note: OSHA=Occupational Safety and Health Administration; NIOSH=National Institute for Occupational Safety and Health; $N=$ number of samples; Above LOD N (\%)=number and percentage of samples above the limit of detection (LOD); < indicates below the limit of detection; <= indicates less than or equal to the limit of detection; $p p b=$ parts per billion. 
Table A3. Instantaneous* evacuated canister task-based air sampling concentration results, NIOSH industrial hygiene survey at roasting and packaging facility, March 2016.

\begin{tabular}{|l|c|c|c|}
\hline \multicolumn{1}{|c}{ Task Description } & $\begin{array}{c}\text { Diacetyl } \\
\text { (ppb) }\end{array}$ & $\begin{array}{c}\text { 2,3-Pentanedione } \\
\text { (ppb) }\end{array}$ & $\begin{array}{c}\text { 2,3-Hexanedione } \\
\text { (ppb) }\end{array}$ \\
\hline Grinding for packaging \#1 & 42.9 & 37.6 & 1.7 \\
Grinding for packaging \#2 & 12.6 & 13.4 & 3.8 \\
Grinding for packaging \#3 & 5.5 & 3.9 & 2.5 \\
Grinding for packaging \#4 & 458 & 431 & 10.5 \\
Grinding for packaging \#5 & 310 & 268 & 17.4 \\
Grinding for packaging \#6 & 55.9 & 53.5 & 4.0 \\
Grinding for packaging \#7 & 363 & 322 & 8.5 \\
Grinding for packaging \#8 & 8.6 & 6.5 & $<1.0$ \\
Grinding for packaging \#9 & 10.0 & 7.6 & 3.1 \\
Grinding for packaging \#10 & 7.5 & 7.0 & 2.7 \\
Packaging with auto-fill machine \#1 & 7.2 & 3.3 & $<1.0$ \\
Packaging with auto-fill machine \#2 & 5.5 & 4.7 & 1.1 \\
Grinding for roast depth \#1 & 66.1 & 45.8 & 2.7 \\
Grinding for roast depth \#2 & 2.2 & 1.7 & 1.0 \\
Grinding for roast depth \#3 & 0.3 & 0.4 & $<0.6$ \\
Grinding for roast depth \#4 & 4.1 & 3.1 & $<1.0$ \\
Opening roasted bean storage bin & 14.6 & 12.9 & $<1.0$ \\
Transfer of roasted beans from & 2.4 & 2.4 & $<1.0$ \\
cooling bin & & & \\
\hline
\end{tabular}

Note: NIOSH=National Institute for Occupational Safety and Health; ppb=parts per billion; < indicates below the limit of detection.

"Sampling duration approximately 30 seconds; task-based air samples were collected by placing the inlet of the canister sampler in the employee's personal breathing zone as he/she performed work task to mimic exposure. 
Table A4. Instantaneous* evacuated canister source air sampling concentration results, NIOSH industrial hygiene survey at roasting and packaging facility, March 2016.

\begin{tabular}{|c|c|c|c|}
\hline Source Description & $\begin{array}{l}\text { Diacetyl } \\
\text { (ppb) }\end{array}$ & $\begin{array}{l}\text { 2,3-Pentanedione } \\
\text { (ppb) }\end{array}$ & $\begin{array}{c}\text { 2,3-Hexanedione } \\
\text { (ppb) }\end{array}$ \\
\hline Roaster drum door during bean dump into cooling bin \#1 & 50.4 & 15.7 & 2.1 \\
\hline Roaster drum door during bean dump into cooling bin \#2 & 74.0 & 39.0 & 20.3 \\
\hline Roaster drum door during bean dump into cooling bin \#3 & 15.4 & 8.7 & 2.1 \\
\hline Above cooling bin after beans dumped from roaster $\# 1$ & 1.8 & 1.3 & 1.2 \\
\hline Above cooling bin after beans dumped from roaster \#2 & 1.9 & 1.6 & $<1.0$ \\
\hline Above cooling bin after beans dumped from roaster \#3 & 2.3 & 2.3 & 1.1 \\
\hline Grinding sample for roast depth & 5.2 & 4.8 & 3.2 \\
\hline Opening lid into roasted bean storage bin & 107 & 46.9 & 7.1 \\
\hline Auto-fill machine exit point $\# 1$ & 13.3 & 12.0 & 2.1 \\
\hline Auto-fill machine exit point \#2 & 29.0 & 20.0 & 1.5 \\
\hline Auto-fill machine exit point \#3 & 6.8 & 13.4 & $<1.0$ \\
\hline Heat sealing bags & 6.0 & 4.8 & 4.0 \\
\hline Outside sample roaster at first crack & 708 & 502 & 12.8 \\
\hline At sample roaster during bean transfer to cooling tray & 6.0 & 5.2 & 3.2 \\
\hline Quality control - 10.5 gram grind & 49.0 & 47.7 & 3.1 \\
\hline Quality control - pouring espresso & 2.7 & 2.3 & 1.1 \\
\hline Quality control - pouring hot water into coffee grounds & 165 & 174 & 11.3 \\
\hline
\end{tabular}

Note: NIOSH=National Institute for Occupational Safety and Health; ppb=parts per billion; $<$ indicates below the limit of detection.

"Sampling duration approximately 30 seconds; source-based air samples were collected by placing the inlet of the canister sampler near a potential source of exposure. These samples are not a direct measure of worker exposure, but they serve to identify locations or activities that may create exposures.

Table A5. Instantaneous ${ }^{*}$ evacuated canister pre- and post-shift background air sampling results, NIOSH industrial hygiene survey at roasting and packaging facility, March 2016.

\begin{tabular}{|c|c|c|c|c|}
\hline Analyte & $\begin{array}{l}\text { Sample } \\
\text { Type }\end{array}$ & Sample Location & $\begin{array}{l}\text { Pre- or Post- } \\
\text { shift }\end{array}$ & $\begin{array}{c}\text { Concentration } \\
\text { (ppb) }\end{array}$ \\
\hline Diacetyl & Background & Work bench by auto-fill machine & Pre-shift & 0.9 \\
\hline Diacetyl & Background & Work bench by auto-fill machine & Post-shift & 3.4 \\
\hline 2,3-Pentanedione & Background & Work bench by auto-fill machine & Pre-shift & 0.5 \\
\hline 2,3-Pentanedione & Background & Work bench by auto-fill machine & Post-shift & 2.2 \\
\hline 2,3-Hexanedione & Background & Work bench by auto-fill machine & Pre-shift & $<0.6$ \\
\hline 2,3-Hexanedione & Background & Work bench by auto-fill machine & Post-shift & $<0.6$ \\
\hline
\end{tabular}

Note: NIOSH=National Institute for Occupational Safety and Health; $\mathbf{p p b}=$ parts per billion; < indicates below the limit of detection.

"Sampling duration approximately 30 seconds 
Table A6. Bulk coffee sample results using headspace analysis, NIOSH industrial hygiene survey at roasting and packaging facility, March 2016.

\begin{tabular}{|l|ccc|}
\hline Bulk Sample Description & $\begin{array}{c}\text { Diacetyl } \\
\text { (ppb) }\end{array}$ & $\begin{array}{c}\mathbf{2 , 3 - P e n t a n e d i o n e} \\
\text { (ppb) }\end{array}$ & $\begin{array}{c}\mathbf{2 , 3 - H e x a n e d i o n e} \\
\text { (ppb) }\end{array}$ \\
\hline From roaster cooling bin \#1 & 935 & 1,370 & $<207$ \\
From roaster cooling bin \#2 & 1,035 & 1,670 & $<207$ \\
From green bean storage & $<84$ & $<116$ & $<207$ \\
\hline
\end{tabular}

Note: NIOSH=National Institute for Occupational Safety and Health; $p p b=$ parts per billion; < indicates below the limit of detection.

Table A7. Real-time air monitoring for total volatile organic compounds, carbon dioxide, and carbon monoxide, NIOSH industrial hygiene survey at roasting and packaging facility, March 2016.

\begin{tabular}{|l|l|ccc|}
\hline Area sample location & \multicolumn{1}{l}{ Measurement } & Minimum & Maximum & Average \\
\hline Roaster machine & TVOC $(\mathrm{ppb})$ & 10 & 3,046 & 290 \\
Roaster machine & $\mathrm{CO}(\mathrm{ppm})$ & 422 & 627 & 515 \\
Roaster machine & $\mathrm{CO}(\mathrm{ppm})$ & $<0.1$ & 1.3 & 0.2 \\
\hline Auto-fill machine & $\mathrm{TVOC}(\mathrm{ppb})$ & 11 & 1,141 & 401 \\
Auto-fill machine & $\mathrm{CO}(\mathrm{ppm})$ & 456 & 691 & 496 \\
Auto-fill machine & $\mathrm{CO}(\mathrm{ppm})$ & $<0.1$ & 4.0 & 0.3 \\
\hline
\end{tabular}

Note: NIOSH=National Institute for Occupational Safety and Health; TVOC = total volatile organic compounds; $\mathrm{CO}=$ carbon monoxide; $\mathrm{CO}_{2}=$ carbon dioxide; $\mathrm{ppb}=$ parts per billion; $\mathbf{p p m}=$ parts per million; $<$ indicates below the resolution of the instrument. 
Table A8. Prevalence of reported symptoms, NIOSH medical survey at coffee roasting and packaging facility, March 2016

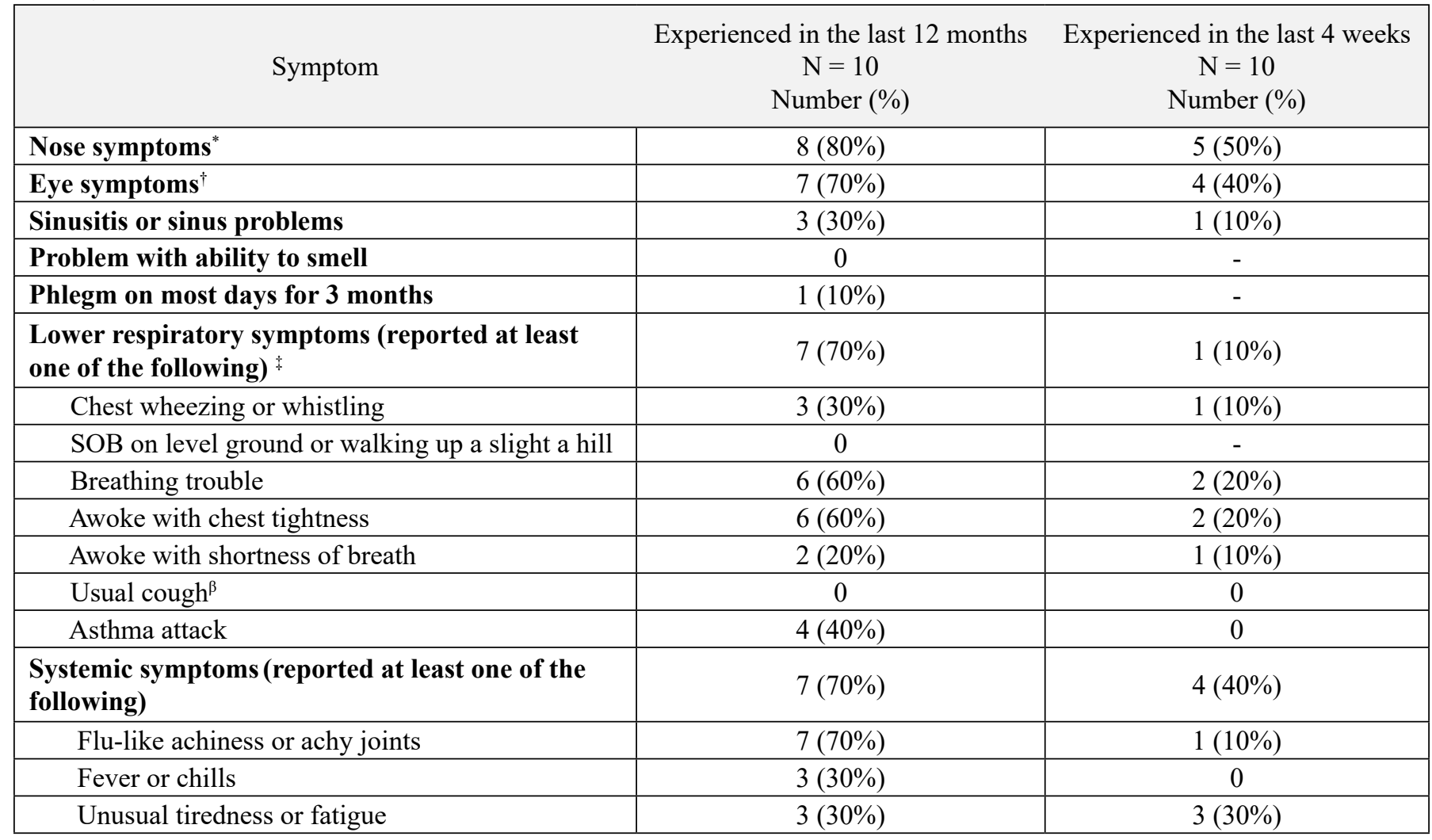

Note: NIOSH=National Institute for Occupational Safety and Health; $\mathbf{N}=$ number of participants; $\mathrm{SOB}=$ shortness of breath; " $"$ " $=$ A four week question was not asked for the symptom.

"Nose symptoms includes one or both of the following: 1) stuffy, itchy, or runny nose or 2) stinging, burning nose.

Eye symptoms includes one or both of the following: 1) watery, itchy eyes or 2) stinging, burning eyes

No participants reported improvement of lower respiratory symptoms away from the workplace. One participant reported green coffee dust caused or aggravated his/her lower respiratory symptoms.

${ }^{\beta}$ This question did not specifically ask about a cough within the past 12 months; participants were asked, "Do you usually have a cough?" If the participants answered yes to that question, they were then asked, "Have you had a cough at any time in the last 4 weeks?" 
Table A9. Adjusted* comparisons of symptoms and self-reported physician diagnosis among NIOSH medical survey participants $(\mathrm{N}=10)$ at coffee roasting and packaging facility to U.S. adult population, March 2016

\begin{tabular}{|c|c|c|c|c|}
\hline Health condition & $\begin{array}{c}\text { Comparative } \\
\text { population }^{\dagger}\end{array}$ & $\begin{array}{c}\text { Observed } \\
\text { Number }\end{array}$ & $\begin{array}{l}\text { Expected } \\
\text { Number }\end{array}$ & $\begin{array}{c}\text { SMR } \\
(95 \% \text { CI })^{\ddagger}\end{array}$ \\
\hline Watery, itchy eyes last 12 months & NHANES III & 6 & 4.3 & $1.4(0.6-3.0)$ \\
\hline Stuffy, itchy, or runny nose last 12 months & NHANES III & 8 & 5.9 & $1.3(0.7-2.7)$ \\
\hline Sinus problems last 12 months & NHANES III & 3 & 4.1 & $0.7(0.3-2.2)$ \\
\hline Phlegm 3 consecutive month or more & NHANES III & 1 & 0.5 & $1.8(0.3-10.5)$ \\
\hline Wheeze last 12 months & NHANES 2007-2012 & 3 & 1.3 & $2.3(0.8-6.8)$ \\
\hline Ever asthma (physician-diagnosed) ${ }^{\beta}$ & NHANES 2007-2012 & 4 & 1.5 & $2.7(1.1-7.0)$ \\
\hline Current asthma (physician-diagnosed) ${ }^{\beta}$ & NHANES 2007-2012 & 4 & 0.8 & $5.1(2.0-13.0)$ \\
\hline
\end{tabular}

Note: NIOSH=National Institute for Occupational Safety and Health; NHANES=National Health and Nutrition Examination Survey; SMR= standardized morbidity ratio.

*Adjusted for sex, race/ethnicity, age, and smoking categories.

We used the most recent NHANES survey available for each comparison.

$\$ 95 \%$ confidence intervals (CIs) that exclude one are statistically significantly different from comparison with US adult population and are shown in bold.

${ }^{\beta}$ Three of the four participants with asthma reported being diagnosed prior to employment at the coffee roasting and packaging facility. 


\section{Appendix B: Café Tables}

Table B1. OSHA Methods 1013/1016 full-shift personal and area air sampling results by location, NIOSH industrial hygiene survey at café, March 2016.

\begin{tabular}{|c|c|c|c|c|c|c|c|}
\hline Analyte & Sample Type & Location & $\mathbf{N}$ & $\begin{array}{c}\text { Above } \\
\text { LOD N } \\
(\%)\end{array}$ & $\begin{array}{c}\text { Minimum } \\
\text { Concentration } \\
(p p b)\end{array}$ & $\begin{array}{c}\text { Maximum } \\
\text { Concentration } \\
(p p b)\end{array}$ & $\begin{array}{c}\text { Above REL } \\
\text { N }\end{array}$ \\
\hline Diacetyl & Personal & Café & 4 & $4(100 \%)$ & 2.2 & 6.0 & 3 \\
\hline Diacetyl & Personal & Kitchen & 1 & $1(100 \%)$ & 2.0 & 2.0 & 0 \\
\hline Diacetyl & Area & Café & 4 & $4(100 \%)$ & 3.7 & 7.3 & N/A \\
\hline 2,3-Pentanedione & Personal & Café & 4 & $4(100 \%)$ & 3.8 & 6.4 & 0 \\
\hline 2,3-Pentanedione & Personal & Kitchen & 1 & $1(100 \%)$ & 2.2 & 2.2 & 0 \\
\hline 2,3-Pentanedione & Area & Café & 4 & $4(100 \%)$ & 3.7 & 7.2 & $\mathrm{~N} / \mathrm{A}$ \\
\hline 2,3-Hexanedione & Personal & Café & 4 & $0(0 \%)$ & $<0.5$ & $<0.6$ & - \\
\hline 2,3-Hexanedione & Personal & Kitchen & 1 & $0(0 \%)$ & $<0.4$ & $<0.4$ & - \\
\hline 2,3-Hexanedione & Area & Café & 4 & $0(0 \%)$ & $<0.4$ & $<0.5$ & N/A \\
\hline
\end{tabular}

Note: OSHA=Occupational Safety and Health Administration; NIOSH=National Institute for Occupational Safety and Health; $N=$ number of samples; Above LOD $N(\%)=$ number and percentage of samples above the limit of detection (LOD); < indicates below the LOD; Above REL N=number of samples above the NIOSH recommended exposure limit (REL); $\mathbf{p p b}=$ parts per billion; N/A indicates that NIOSH RELs are specified for personal air samples, and cannot be directly applied to area air samples; "-_indicates that there is currently no REL for 2,3-hexanedione.

Table B2. OSHA Methods 1013/1016 personal task-based air sampling results, NIOSH industrial hygiene survey at café, March 2016.

\begin{tabular}{|c|c|c|c|c|c|c|}
\hline Analyte & Task & $\mathbf{N}$ & $\begin{array}{c}\text { Above } \\
\text { LOD N } \\
(\%)\end{array}$ & $\begin{array}{c}\text { Minimum } \\
\text { Concentration } \\
(\mathbf{p p b})\end{array}$ & $\begin{array}{c}\text { Maximum } \\
\text { Concentration } \\
(p p b)\end{array}$ & $\begin{array}{c}\text { Sample } \\
\text { Duration } \\
\text { (minutes) }\end{array}$ \\
\hline Diacetyl & Making coffee & 1 & $1(100 \%)$ & 2.6 & 2.6 & 12 \\
\hline Diacetyl & Making espresso & 1 & $1(100 \%)$ & 7.3 & 7.3 & 15 \\
\hline Diacetyl & Miscellaneous tasks & 1 & $0(0 \%)$ & $<1.3$ & $<1.3$ & 16 \\
\hline 2,3-Pentanedione & Making coffee & 1 & $1(100 \%)$ & 2.7 & 2.7 & 12 \\
\hline 2,3-Pentanedione & Making espresso & 1 & $1(100 \%)$ & 9.4 & 9.4 & 15 \\
\hline 2,3-Pentanedione & Miscellaneous tasks & 1 & $1(100 \%)$ & 6.1 & 6.1 & 16 \\
\hline 2,3-Hexanedione & Making coffee & 1 & $0(0 \%)$ & $<1.8$ & $<1.8$ & 12 \\
\hline 2,3-Hexanedione & Making espresso & 1 & $0(0 \%)$ & $<1.4$ & $<1.4$ & 15 \\
\hline 2,3-Hexanedione & Miscellaneous tasks & 1 & $0(0 \%)$ & $<1.4$ & $<1.4$ & 16 \\
\hline
\end{tabular}

Note: OSHA=Occupational Safety and Health Administration; NIOSH=National Institute for Occupational Safety and Health; $N=$ number of samples; Above LOD $N(\%)=$ number and percentage of samples above limit of detection (LOD); < indicates below the LOD. 
Table B3. Instantaneous* evacuated canister task-based air sampling concentration results, NIOSH industrial hygiene survey at café, March 2016.

\begin{tabular}{|l|c|c|c|}
\hline Task Description & $\begin{array}{c}\text { Diacetyl } \\
\text { (ppb) }\end{array}$ & $\begin{array}{c}\text { 2,3-Pentanedione } \\
\text { (ppb) }\end{array}$ & $\begin{array}{c}\text { 2,3-Hexanedione } \\
\text { (ppb) }\end{array}$ \\
\hline Grinding for espresso \#1 & 6.5 & 6.6 & $<1.0$ \\
Grinding for espresso \#2 & 14.3 & 14.2 & 4.4 \\
Pouring espresso & 12.8 & 13.3 & 6.5 \\
Melting chocolate with hot water & 16.8 & 16.1 & 2.2 \\
Steaming milk & 9.0 & 9.1 & 2.7 \\
\hline
\end{tabular}

Note: NIOSH=National Institute for Occupational Safety and Health; $\mathrm{ppb}=$ parts per billion; $<$ indicates below the limit of detection.

"Sampling duration approximately 30 seconds; task-based air samples were collected by placing the inlet of the canister sampler in the employee's personal breathing zone as he/she performed work task to mimic exposure.

Table B4. Instantaneous* evacuated canister source air sampling concentration results, NIOSH industrial hygiene survey at café, March 2016.

\begin{tabular}{|l|c|c|c|}
\hline Source Description & $\begin{array}{c}\text { Diacetyl } \\
\text { (ppb) }\end{array}$ & $\begin{array}{c}\text { 2,3-Pentanedione } \\
\text { (ppb) }\end{array}$ & $\begin{array}{c}\text { 2,3-Hexanedione } \\
\text { (ppb) }\end{array}$ \\
\hline Changing grinder settings & 8.4 & 9.0 & 1.9 \\
Grinding for bulk brew & 215 & 229 & 8.1 \\
Grinding for espresso & 54.2 & 50.9 & 5.5 \\
Grinding for pour over \#1 & 33.8 & 35.3 & 6.5 \\
Grinding for pour over \#2 & 94.0 & 9.6 & 6.1 \\
Making a pour over drink & 8.9 & 3.9 & 3.0 \\
Frothing milk from steam wand & 5.0 & 12.1 & $<0.9$ \\
Melting chocolate with hot water & 12.2 & 9.1 & 8.1 \\
\hline
\end{tabular}

Note: NIOSH=National Institute for Occupational Safety and Health; $\mathbf{p p b}=$ parts per billion; < indicates below the limit of detection.

"Sampling duration approximately 30 seconds; source-based air samples were collected by placing the inlet of the canister sampler near a potential source of exposure. These samples are not a direct measure of worker exposure, but they serve to identify locations or activities that may create exposures. 
Table B5. Instantaneous* evacuated canister pre- and post -shift background air sampling results, NIOSH industrial hygiene survey at café, March 2016.

\begin{tabular}{|l|llcc|}
\hline Analyte & Sample Type & Sample Location & $\begin{array}{c}\text { Pre- or Post- } \\
\text { shift }\end{array}$ & $\begin{array}{c}\text { Concentration } \\
\text { (ppb) }\end{array}$ \\
\hline Diacetyl & Background & Between service bar and seating area & Pre-shift & 3.0 \\
Diacetyl & Background & Between service bar and seating area & Post-shift & 6.0 \\
\hline 2,3-Pentanedione & Background & Between service bar and seating area & Pre-shift & 2.1 \\
2,3-Pentanedione & Background & Between service bar and seating area & Post-shift & 5.4 \\
\hline 2,3-Hexanedione & Background & Between service bar and seating area & Pre-shift & $<0.6$ \\
2,3-Hexanedione & Background & Between service bar and seating area & Post-shift & $<0.6$ \\
\hline
\end{tabular}

Note: $\mathrm{NIOSH}=$ National Institute for Occupational Safety and Health; $\mathbf{p p b}=$ parts per billion; < indicates below the limit of detection.

"Sampling duration approximately 30 seconds

Table B6. Real-time air monitoring for total volatile organic compounds, carbon dioxide, and carbon monoxide, NIOSH industrial hygiene survey at café, March 2016.

\begin{tabular}{|l|l|c|c|c|}
\hline Area Sample Location & Measurement & \multicolumn{2}{c}{ Minimum } & \multicolumn{2}{c|}{ Maximum } & Average \\
\hline Beside Grinders & TVOC $(\mathrm{ppb})$ & 99 & 25,444 & 917 \\
\hline Beside Grinders & $\mathrm{CO}_{2}(\mathrm{ppm})$ & 1,628 & 1,969 & 1,811 \\
\hline Beside Grinders & $\mathrm{CO}(\mathrm{ppm})$ & 0.3 & 109.6 & 1.6 \\
\hline
\end{tabular}

Note: NIOSH=National Institute for Occupational Safety and Health; ppb=parts per billion; $p$ pm=parts per million; $\mathrm{TVOC}=$ total volatile organic compounds; $\mathrm{CO}=$ carbon monoxide; $\mathrm{CO}_{2}=$ carbon dioxide. 


\section{Appendix C: Figures}

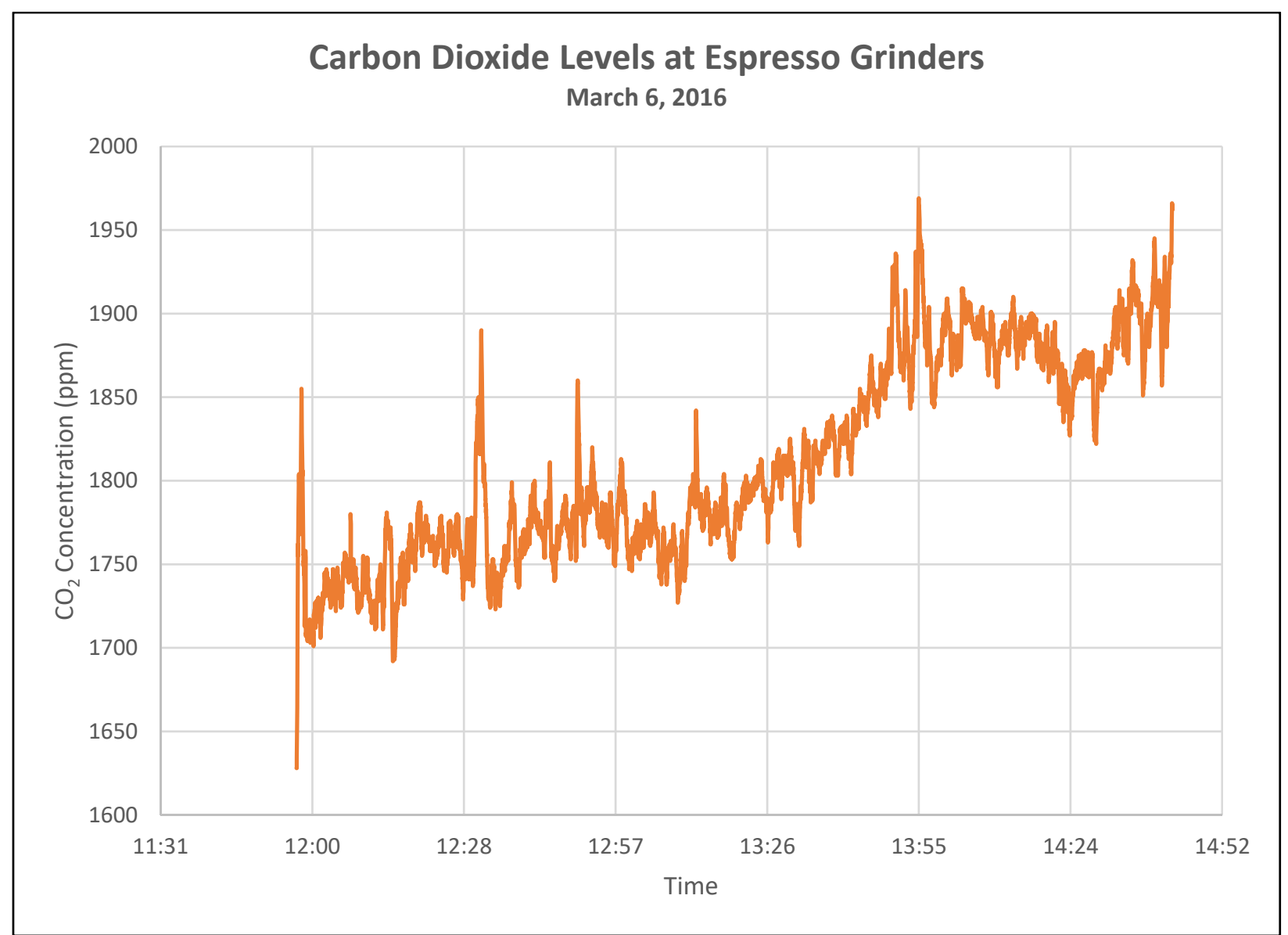

Figure 1. Measured carbon dioxide $\left(\mathrm{CO}_{2}\right)$ concentrations in parts per million (ppm) near the espresso grinders behind the service bar of the café on March 6, 2016. 


\section{References}

Abeygunasekera DD, Jansz ER [1989]. Effect of the maturation process on fermented cocoa bean I: free amino acids and volatile carbonyls. J Natn Sci Coun Sri Lanka 17(1):23-33.

ACGIH (American Conference of Governmental Industrial Hygienists) [2017a]. 2017 TLVs ${ }^{\circledR}$ and BEIs ${ }^{\circledR}$ : Threshold limit values for chemical substances and physical agents and biological exposure indices. Cincinnati, OH: American Conference of Governmental Industrial Hygienists.

ACGIH [2017b]. Chemicals Substances and Other Issues Under Study (TLV ${ }^{\circledR}$-CS). Available at: http://www.acgih.org/tlv-bei-guidelines/documentation-publications-and-data/understudy-list/chemical-substances-and-other-issues-under-study-tlv. Date accessed: April 2018.

Aculey PC, Snitkjaer P, Owusu M, Bassompiere M, Takrama J, Nørgaard L, Petersen MA, Nielsen DS [2010]. Ghanaian cocoa bean fermentation characterized by spectroscopic and chromatographic methods and chemometrics. J Food Sci 75(6):S300-307.

Akiyama M, Murakami K, Ohtani N, Iwatsuki K, Sotoyama K, Wada A, Tokuno K, Iwabuchi $\mathrm{H}$, Tanaka K [2003]. Analysis of volatile compounds released during the grinding of roasted coffee beans using solid-phase microextraction. J Agric Food Chem 51(7):1961-1969.

Anderson BA, Shimoni E, Liardon R, Labuza P [2003]. The diffusion kinetics of carbon dioxide in fresh roasted and ground coffee. J Food Eng 59:71-78.

ANSI (American National Standards Institute)/ASHRAE [2016]. Ventilation for acceptable indoor air quality, standard 62.1-2016. Atlanta, GA: ASHRAE.

Bailey RL, Cox-Ganser JM, Duling MG, LeBouf RF, Martin SB Jr, Bledsoe TA, Green BJ, Kreiss K [2015]. Respiratory morbidity in a coffee processing workplace with sentinel obliterative bronchiolitis cases. Am J Ind Med 58(12):1235-1245.

Burney P, Chinn S [1987]. Developing a new questionnaire for measuring the prevalence and distribution of asthma. Chest 91 (6 Suppl):79S-83S.

Burney PG, Laitinen LA, Perdrizet S, Huckauf H, Tattersfield AE, Chinn S, Poisson N, Heeren A, Britton JR, Jones T [1989]. Validity and repeatability of the IUATLD (1984) Bronchial symptoms questionnaire: an international comparison. Eur Respir J 2(10):940-945.

Burney PG, Luczynska C, Chinn S, Jarvis D [1994]. The European community respiratory health survey. Eur Respir J 7(5):954-960.

CDC (Centers for Disease Control and Prevention) [1996]. Third National Health and Nutrition Examination Survey, 1988-1994, NHANES III Examination Data File [CDROM]. Hyattsville, Maryland: U.S. Department of Health and Human Services, Centers for Disease 
Control and Prevention. (Public use data file documentation No. 76300).

CDC [2013a]. Obliterative bronchiolitis in workers in a coffee-processing facility-Texas, 2008-2012. Morb Mortal Wkly Rep 62(16):305-307.

CDC [2013b]. Carbon Monoxide Poisoning. Available at: https://www.cdc.gov/co/default. htm. Date accessed: Date accessed: April 2018.

CDC [2017]. Smoking \& tobacco use: quit smoking. Available at: https://www.cdc.gov/ tobacco/quit_smoking/index.htm. Date accessed: April 2018.

CDC [2018]. National Center for Health Statistics. National Health and Nutrition Examination Survey Data. Hyattsville, MD: U.S. Department of Health and Human Services, Centers for Disease Control and Prevention, [2007-2012] Available at: https://wwwn.cdc. gov/nchs/nhanes/default.aspx. Date accessed: April 2018.

CFR. Code of Federal Regulations. Washington, DC: U.S. Government Printing Office, Office of the Federal Register.

Cockcroft D, Davis B [2009]. Direct and indirect challenges in the clinical assessment of asthma. Ann Allergy Asthma Immunol 103(5):363-369.

Daglia M, Papetti A, Aceti C, Sordelli B, Spini V, Gazzani G [2007]. Isolation and determination of $\alpha$-dicarbonyl compounds by RP-HPLC-DAD in green and roasted coffee. J Agric and Food Chem 55(22):8877-8882.

Day G, LeBouf R, Grote A, Pendergrass S, Cummings K, Kreiss K, and Kullman G [2011]. Identification and measurement of diacetyl substitutes in dry bakery mix production. J Occ Env Hygiene 8(2):93-103.

Duling MG, LeBouf RF, Cox-Ganser JM, Kreiss K, Martin SB Jr, Bailey RL [2016]. Environmental characterization of a coffee processing workplace with obliterative bronchiolitis in former workers. J Occup Environ Hyg 13(10):770-781.

Dweik RA, Boggs PB, Erzurum SC, Irvin CG, Leigh MW, Lundberg JO, Olin AC, Plummer AL, Taylor DR; American Thoracic Society Committee on Interpretation of Exhaled Nitric Oxide Levels (FENO) for Clinical Applications [2011]. An official ATS clinical practice guideline: interpretation of exhaled nitric oxide levels (FENO) for clinical applications. Am J Respir Crit Care Med 184(5):602-615.

EAACI Task Force on Occupational Rhinitis, Moscato G, Vandenplas O, Gerth Van Wijk R, Malo JL, Quirce S, Walusiak J, Castano R, De Groot H, Folletti I, Gautrin D, Yacoub MR, Perfetti L, Siracusa A [2008]. Occupational rhinitis. Allergy 63(8):969-980. 
ECRHS (European Community Respiratory Health Survey)[2014]. Questionnaires, protocols and instructions. Available at: http://www.ecrhs.org/Quests.htm. Date accessed: April 2018.

Ferris BG [1978]. Epidemiology standardization project. Am Rev Respir Dis 118(Suppl):1-53.

Figley KD, Rawling FF [1950] Castor bean: an industrial hazard as a contaminant of green coffee dust and used burlap bags. J Allergy 21:545-553.

Ghanei M, Tazelaar HD, Chilosi M, Harandi AA, Peyman M, Akbari HM, Shamsaei H, Bahadori M, Aslani J, Mohammadi A [2008]. An international collaborative pathologic study of surgical lung biopsies from mustard gas-exposed patients. Respir Med 102(6):825-30.

Grassi M, Rezzani C, Biino G, Marinoni A [2003]. Asthma-like symptoms assessment through ECRHS screening questionnaire scoring. J Clin Epidemiol 56(3):238-247.

Hankinson JL, Odencrantz JR, Fedan KB [1999]. Spirometric reference values from a sample of the general U.S. population. Am J Respir Crit Care Med 159(1):179-187.

Henneberger PK, Redlich CA, Callahan DB, Harber P, Lemière C, Martin J, Tarlo SM, Vandenplas O, Torén K; ATS Ad Hoc Committee on Work-Exacerbated Asthma [2011]. An official American Thoracic Society statement: work-exacerbated asthma. Am J Respir Crit Care Med 184(3):368-378.

Hubbs AF, Cumpston AM, Goldsmith WT, Battelli LA, Kashon ML, Jackson MC, Frazer DG, Fedan JS, Goravanahally MP, Castranova V, Kreiss K, Willard PA, Friend S, SchweglerBerry D, Fluharty KL, Sriram K [2012]. Respiratory and olfactory cytotoxicity of inhaled 2,3-pentanedione in Sprague-Dawley rats. Am J Pathol 181(3):829-844.

Kanwal R, Kullman G, Piacitelli C, Boylstein R, Sahakian N, Martin S, Fedan K, Kreiss K [2006]. Evaluation of flavorings-related lung disease risk at six microwave popcorn plants. J Occup Environ Med. 48(2):149-57.

Karr RM, Davies RJ, Butcher BT, Lehrer SB, Wilson MR, Dharmarajan V, Salvaggio JE [1978]. Occupational asthma. J Allergy Clin Immunol 61(1):54-65.

Kim TJ, Materna BL, Prudhomme JC, Fedan KB, Enright PL, Sahakian NM, Windham GC, Kreiss K [2010]. Industry-wide medical surveillance of California flavor manufacturing workers: Cross-sectional results. Am J Ind Med 53(9):857-865.

King MS, Eisenberg R, Newman JH, Tolle JJ, Harrell FE Jr, Nian H, Ninan M, Lambright ES, Sheller JR, Johnson JE, Miller RF [2011]. Constrictive bronchiolitis in soldiers returning from Iraq and Afghanistan. N Engl J Med 365(3):222-230.

Kreiss K [2013]. Occupational causes of constrictive bronchiolitis. Curr Opin Allergy Clin Immunol 13(2):167-172. 
Langford NJ [2005]. Carbon dioxide poisoning. Toxicol Rev 24(4):229-235.

LeBouf RF, Stefaniak AB, Virji, MA [2012]. Validation of evacuated canisters for sampling volatile organic compounds in healthcare settings. J Environ Monit 14(3):977-983.

LeBouf RF and Simmons M [2017]. Increased sensitivity of OSHA method analysis of diacetyl and 2,3-pentanedione in air. J Occup Environ Hyg 14(5):343-348.

Lehrer SB, Karr RM, Salvaggio JE [1978]. Extraction and analysis of coffee bean allergens. Clin Allergy 8(3):217-226.

Miller MR, Hankinson J, Brusasco V, Burgos F, Casaburi R, Coates A, Crapo R, Enright P, van der Grinten CP, Gustafsson P, Jensen R, Johnson DC, MacIntyre N, McKay R, Navajas D, Pedersen OF, Pellegrino R, Viegi G, Wanger J, ATS/ERS Task Force [2005]. Standardisation of spirometry. Eur Respir J 26(2):319-338.

Morgan DL, Jokinen MP, Price HC, Gwinn WM, Palmer SM, Flake GP [2012]. Bronchial and bronchiolar fibrosis in rats exposed to 2,3-pentanedione vapors: implications for bronchiolitis obliterans in humans. Toxicol Pathol 40(3):448-465.

Morgan DL, Jokinen MP, Johnson CL, Price HC, Gwinn WM, Bousquet RW, Flake GP [2016]. Chemical reactivity and respiratory toxicity of the $\alpha$-diketone flavoring agents: 2,3-butanedione, 2,3-pentanedione, and 2,3-hexanedione. Toxicol Pathol 44(5):763-783.

Newton J [2002]. Carbon monoxide exposure from coffee roasting. Appl Occup Environ Hyg. 17(9):600-602.

NIOSH (National Institute for Occupational Safety and Health) [2003]. NIOSH manual of analytical methods (NMAM $\left.{ }^{\circledR}\right)$. 4th ed. Schlecht PC, O’Connor PF, eds. Cincinnati, OH: U.S. Department of Health and Human Services, Centers for Disease Control and Prevention, National Institute for Occupational Safety and Health, DHHS (NIOSH) Publication 94-113 (August 1994); 1st Supplement Publication 96-135, 2nd Supplement Publication 98-119; 3rd Supplement 2003-154. Available at: http://www.cdc.gov/niosh/docs/2003-154/.

NIOSH [2004]. NIOSH respirator selection logic. Cincinnati, OH: U.S. Department of Health and Human Services, Public Health Service, Centers for Disease Control, National Institute for Occupational Safety and Health, DHHS (NIOSH). Publication No. 2005100 Available at: http://www.aresok.org/npg/nioshdbs/docs/2005-100/chapter2.html. Date accessed: April 2018.

NIOSH [2010]. NIOSH pocket guide to chemical hazards. Cincinnati, OH: U.S. Department of Health and Human Services, Centers for Disease Control and Prevention, National Institute for Occupational Safety and Health, DHHS (NIOSH) Publication No. 2010-168c Available at: http://www.cdc.gov/niosh/npg/. Date accessed: April 2018. 
NIOSH [2012]. Flavoring-related lung disease. Information for healthcare providers. Department of Health and Human Services, Centers for Disease Control and Prevention, DHHS (NIOSH) Publication No. 2012-148 (supersedes 2012-107). Available at: http://www. cdc.gov/niosh/docs/2012-148/. Date accessed: April 2018.

NIOSH [2016]. Criteria for a recommended standard: occupational exposure to diacetyl and 2,3-pentanedione. U.S. Department of Health and Human Services, Centers for Disease Control and Prevention, National Institute for Occupational Safety and Health, DHHS (NIOSH) Publication No. 2016-111. Available at: https:/www.cdc.gov/niosh/docs/2016-111/. Date accessed: April 2018.

NIOSH [2017]. Work-related asthma. Available at: https:/www.cdc.gov/niosh/topics/asthma/ default.html. Date accessed: April 2018.

Nishimura F, Abe S, Fukunaga T [2003]. Carbon monoxide poisoning from industrial coffee extraction. JAMA 290(3):334.

Ohashi Y, Motojima S, Fukuda T, Makino S [1992]. Airway hyperresponsiveness, increased intracellular spaces of bronchial epithelium, and increased infiltration of eosinophils and lymphocytes in bronchial mucosa in asthma. Am Rev Respir Dis 145(6):1469-1476.

Oldenburg M, Bittner C, Baur X [2009]. Health risks due to coffee dust. Chest 136(2):536544.

Oppenheimer BW, Goldring RM, Herberg ME, Hofer IS, Reyfman PA, Liautaud S, Rom WN, Reibman J, Berger KI [2007]. Distal airway function in symptomatic subjects with normal spirometry following World Trade Center dust exposure. Chest 132(4):1275-1282.

OSHA (Occupational Safety and Health Administration) [1993]. Compliance and Enforcement Activities Affected by the PELs Decision. August 5, 1993 Memorandum. Available at: https://www.osha.gov/pls/oshaweb/owadisp.show document?p table=INTERPRETATIONS\&p id=21220. Date accessed: April 2018.

OSHA [2003]. Enforcement Policy for Respiratory Hazards Not Covered by OSHA Permissible Exposure Limits. January 24, 2003 Memorandum. Available at: https://www. osha.gov/pls/oshaweb/owadisp.show document?p table=INTERPRETATIONS\&p $\underline{\mathrm{id}=24749}$. Date accessed: April 2018.

OSHA [2008]. Sampling and analytical methods: Method 1013 - Acetoin and diacetyl. Available at: http://www.osha.gov/dts/sltc/methods/validated/1013/1013.html. Date accessed: April 2018.

OSHA [2010]. Sampling and analytical methods: Method 1016 - 2,3-pentanedione. Available at: http://www.osha.gov/dts/sltc/methods/validated/1016/1016.html. Date accessed: April 2018. 
OSHA [2014]. OSHA fact sheet: Do you have work-related asthma? A guide for you and your doctor. Washington, D.C.: U.S. Department of Labor, Occupational Safety and Health Administration. Available at: https://www.osha.gov/Publications/OSHA3707.pdf. Date accessed: April 2018.

OSHA [2016]. Permissible exposure limits - annotated tables. Available at: https://www. osha.gov/dsg/annotated-pels/index.html. Date accessed: April 2018.

Pellegrino R, Viegi G, Brusasco V, Crapo RO, Burgos F, Casaburi R, Coates A, van der Grinten CP, Gustafsson P, Hankinson J, Jensen R, Johnson DC, MacIntyre N, McKay R, Miller MR, Navajas D, Pedersen OF, Wanger J [2005]. Interpretative strategies for lung function tests. Eur Respir J 26(5):948-968.

Perez T, Chanez P, Dusser D, Devillier P [2013]. Small airway impairment in moderate to severe asthmatics without significant proximal airway obstruction. Respir Med 2013 Nov;107(11):1667-1674.

Raffel JB, Thompson J [2013]. Carbon monoxide from domestic coffee roasting: a case report. Ann Intern Med 159(11):795-796.

Rondón C, Campo P, Galindo L, Blanca-López N, Cassinello MS, Rodriguez-Bada JL, Torres MJ, Blanca M [2012]. Prevalence and clinical relevance of local allergic rhinitis. Allergy 67(10):1282-1288.

Rondón C, Bogas G, Barrionuevo E, Blanca M, Torres MJ, Campo P [2017]. Nonallergic rhinitis and lower airway disease. Allergy 72(1):24-34.

Rose JJ, Wang L, Xu Q, McTiernan CF, Shiva S, Tejero J, Gladwin MT [2017]. Carbon monoxide poisoning: pathogenesis, management, and future directions of therapy. Am J Respir Crit Care Med 195(5):596-606.

Sahay S, Gera K, Bhargava SK, Shah A [2016]. Occurrence and impact of sinusitis in patients with asthma and/or allergic rhinitis. J Asthma 53(6):635-643.

Sakwari G, Mamuya SH, Bråtveit M, Moen BE [2013]. Respiratory symptoms, exhaled nitric oxide, and lung function among workers in Tanzanian coffee factories. J Occup Environ Med 55(5):544-551.

Shaaban R, Zureik M, Soussan D, Neukirch C, Heinrich J, Sunyer J, Wjst M, Cerveri I, Pin I, Bousquet J, Jarvis D, Burney PG, Neukirch F, Leynaert B [2008]. Rhinitis and onset of asthma: a longitudinal population-based study. Lancet. 372(9643):1049-1057.

Shibamoto T [2014]. Diacetyl: occurrence, analysis, and toxicity. J Agric Food Chem 62(18):4048-4053. 
Smith HJ, Reinhold P, Goldman MD [2005]. Forced oscillation technique and impulse oscillometry. In: Gosselink R, Stam H, eds. European Respiratory Monograph 31: Lung Function Testing. Vol. 10. Wakefield, UK: European Respiratory Society Journals, pp. 72105.

Smith HJ (Hans-Juergen.Smith@CareFusion.com) [2015]. Questions about impulse oscillometry. Email of December 9, 2015, from Hans-Juergen Smith, CareFusion, to Rachel Bailey (feu2@cdc.gov), Respiratory Health Division, National Institute for Occupational Safety and Health, Centers for Disease Control and Prevention, Department of Health and Human Services.

Tarlo SM, Lemiere C [2014]. Occupational asthma. N Engl J Med 370:640-649.

Tarlo SM [2016].Update on work-exacerbated asthma. Int J Occup Med Environ Health 29(3):369-374.

Thomas KE, Trigg CJ, Baxter PJ, Topping M, Lacey J, Crook B, Whitehead P, Bennett JB, Davies RJ. [1991]. Factors relating to the development of respiratory symptoms in coffee process workers. Br J Ind Med 48(5):314-322.

Usmani OS, Singh D, Spinola M, Bizzi A, Barnes PJ [2016].The prevalence of small airways disease in adult asthma: A systematic literature review. Respir Med 116:19-27.

Vogel J, Smidt U [1994] Impulse oscillometry. analysis of lung mechanics in general practice and clinic, epidemiological and experimental research. 1st ed. Frankfurt: PMI-Verlagsgruppe.

Weinstein DJ, Hull JE, Ritchie BL, Hayes JA, Morris MJ [2016]. Exercise-associated excessive dynamic airway collapse in military personnel. Ann Am Thorac Soc 13(9):14761482.

Zuskin E, Valić F, Skurić Z [1979]. Respiratory function in coffee workers. Br J Ind Med 36(2):117-122.

Zuskin E, Kanceljak B, Skurić Z, Butković D [1985]. Bronchial reactivity in green coffee exposure. Br J Ind Med 42(6):415-420.

Zuskin E, Schachter EN, Kanceljak B, Witek TJ Jr, Fein E [1993]. Organic dust disease of airways. Int Arch Occup Environ Health 65(2):135-140. 
This page left intentionally blank 
Keywords: NAICS 311920 (Coffee roasting), Wisconsin, diacetyl, 2,3-pentanedione, 2,3-hexanedione, coffee, café, carbon monoxide, carbon dioxide, volatile organic compounds (VOCs). 
The Health Hazard Evaluation Program investigates possible health hazards in the workplace under the authority of the Occupational Safety and Health Act of 1970 (29 U.S.C. § 669(a) (6)). The Health Hazard Evaluation Program also provides, upon request, technical assistance to federal, state, and local agencies to investigate occupational health hazards and to prevent occupational disease or injury. Regulations guiding the Program can be found in Title 42, Code of Federal Regulations, Part 85; Requests for Health Hazard Evaluations (42 CPR Part 85).

\section{Disclaimer}

The recommendations in this report are made on the basis of the findings at the workplace evaluated and may not be applicable to other workplaces.

Mention of any company or product in this report does not constitute endorsement by the National Institute for Occupational Safety and Health (NIOSH).

Citations to Web sites external to NIOSH do not constitute NIOSH endorsement of the sponsoring organizations or their programs or products. NIOSH is not responsible for the content of these Web sites. All Web addresses referenced in this document were accessible as of the publication date.

\section{Acknowledgments}

Desktop Publisher: Tia McClelland

Data Analysis Support: Nicole Edwards, Kathleen Fedan, and Brian Tift

NIOSH Laboratory Assistance: Dru Burns, Kyle Hatcher, Ryan LeBouf, Anand Ranpara

Site Visit Team Members: Rachel Bailey, Matthew Duling, Alyson Johnson, Stephen Martin, Christopher Mugford, Marcia Stanton, and Brian Tift

\section{Availability of Report}

Copies of this report have been sent to the employer, employees, and union at the facility. The state and local health department and the Occupational Safety and Health Administration Regional Office have also received a copy. This report is not copyrighted and may be freely reproduced.

This report is available at http://www.cdc.gov/niosh/hhe/reports/pdfs/2016-0067-3313.pdf. All other HHE Reports may be found at http://www2a.cdc.gov/hhe/search.asp

\section{Recommended citation for this report:}

$\mathrm{NIOSH}$ [2018]. Health hazard evaluation report: evaluation of exposures and respiratory health at a coffee roasting and packaging facility and associated café. By Martin SB, LeBouf RF, Stanton ML, Bailey RL. Morgantown, WV: U.S. Department of Health and Human Services, Centers for Disease Control and Prevention, National Institute for Occupational Safety and Health, NIOSH HHE Report No. 2016-0067-3313. 
Delivering on the Nation's promise:

Safety and health at work for all people through research and prevention

To receive documents or other information about occupational safety and health topics, contact NIOSH

Telephone: 1-800-CDC-INFO (1-800-232-4636)

TTY: 1-888-232-6348

email: cdcinfo@cdc.gov

or visit the NIOSH website at http://www.cdc.gov/niosh

SAFER • HEALTHIER $\cdot$ PEOPLE $^{\text {TM }}$ 